\title{
Study on the germination of nano-TiO 2 synthetic seeds and the physiology of Dendrobium officinale regenerated plants
}

Jiemin Guan ( $D$ 87662216@qq.com )

University of Hong Kong

Xiaoping Lai

Guangzhou University of Chinese Medicine

Guifang Zhang

Guangzhou University of Chinese Medicine

Shijie Li

Guangzhou University of Chinese Medicine

Jiexian Guan

Tang Guan Food Trading Co. Ltd.

\section{Baohua Li}

Tang Guan Food Trading Co. Ltd.

\section{Nano Express}

Keywords: nano-TiO2; synthetic seeds; germination; regenerated plants; physiology

Posted Date: February 19th, 2020

DOl: https://doi.org/10.21203/rs.2.24015/v1

License: (1) This work is licensed under a Creative Commons Attribution 4.0 International License.

Read Full License 


\title{
Study on the germination of nano- $\mathrm{TiO}_{2}$ synthetic seeds and the physiology of Dendrobium officinale regenerated plants
}

Jiemin Guan ${ }^{1,2,3^{*}}$, Xiaoping Lai ${ }^{2,4}$, Guifang Zhang ${ }^{4}$, Shijie $\mathrm{Li}^{4}$, Jiexian Guan ${ }^{3}$, Baohua $\mathrm{Li}^{3}$

${ }^{1}$ Department of Chemistry, The University of Hong Kong, Hongkong, China.

${ }^{2}$ Mathematical Engineering Academy of Chinese Medicine, Guangzhou University of Chinese Medicine, Guangdong, China.

${ }^{3}$ Tang Guan Food Trading Co. , Ltd., Guangzhou, China.

${ }^{4}$ School of Chinese Materia Medica, Guangzhou University of Chinese Medicine, Guangzhou, China.

*email: jieminguan@126.com

\begin{abstract}
Synthetic seed of biological technology has been suggested as an effective strategy to improve breeding. Nano- $\mathrm{TiO}_{2}$ is a photosemiconductor material widely used in life science and agriculture. Nano- $\mathrm{TiO}_{2}$ has been recently shown to improve photosynthetic function, promote plant growth and development, but the physiology mechanism is still unclear. The aim of the current study was to confirm whether or not nano- $\mathrm{TiO}_{2}$ synthetic seed has an effect on germination and physiology of Dendrobium officinale. Using $D$. officinale protocorm models, we demonstrate that appropriate nano- $\mathrm{TiO}_{2}$ leads to growth and development of germination seedlings, and improves the root activity, nitrate reductase activity and antioxidant system activity. Our data also provide a basis for the improvement of the preparation process and practical production of $D$. officinale synthetic seeds.
\end{abstract}

Keywords: nano- $\mathrm{TiO}_{2}$; synthetic seeds; germination; regenerated plants; physiology

\section{Introduction}

Synthetic seed is a kind of small granule which can develop into a complete plant under suitable conditions by using the totipotency of cells to wrap the somatic embryo or meristem which can develop into a complete plant in vitro culture into an outer membrane which contains nutrients and has protective function. As a new biological technology, synthetic seed has made great progress after more than 20 years of research, and it has been reported that it can germinate into seedlings or be used in 
field and greenhouse production. Alginate encapsulated somatic embryos have many kinds of advantages over organogenesis for propagation, including long-term storage, higher scale-up potential and low cost of production[1]. In recent years, the research on synthetic seeds has shifted from the early model plants (such as alfalfa[2] and Sandalwood[3]) to numerous crops (such as conifers[4] and pistachio[5]), aquatic macrophytes[6] and commercial plants (such as Paulownia elongata[7]), but only very few in Orchidaceae species.

The complete synthetic seed includes three basic parts: synthetic embryo, synthetic endosperm and synthetic seed coat. At present, the synthetic seed embryo has developed from embryoid to some embryo analogues, such as adventitious buds and protocorms[8]. synthetic endosperm provides nutrients and growth regulators for the metabolism and development of synthetic embryo. In addition, active carbon, natural organic matter, fungicide, herbicide and other substances can be added to the synthetic endosperm. The synthetic seed coat, as the natural seed coat, is a protective membrane wrapped outside the synthetic embryo and endosperm. It not only prevents the loss of water and nutrition in the seed, but also ensures ventilation and prevents the pressure brought by external mechanical shock. Alginate, gelatin, sodium pectinate, agar, Gel-rite-TM, chitosan and polyethylene glycol are suitable for synthetic seed coat, and sodium alginate is the most widely studied and applied in synthetic seed coat[7].

At present, there are few reports about the synthetic seeds of D. officinale. Sodium alginate embedding system is convenient and has high germination rate, but its water retention is poor, it is easy to air dry quickly in the air and contaminate miscellaneous bacteria, and the growth of germinating seedlings is not consistent, there will be secondary seedlings or secondary protocorms, and some will even be deformed, not rod, rootless or root thick. Therefore, it is necessary to optimize the preparation conditions of $D$. officinale synthetic seeds, so as to lay the foundation for its practical use and large-scale production.

There are multiple nano materials, each with different functions and applications, among which nano- $\mathrm{TiO}_{2}$ is widely used in life science and agriculture[9-10]. At present, few reports show that the photobiological effects are induced by photosemiconductor material nano- $\mathrm{TiO}_{2}$ in living plants, such as improving photosynthetic function[11], promoting plant growth and development[12-13]. The present route enables the utilization of nanoparticles synthesized under any conditions as the starting seeds for nanomaterial growth inside protein nanocages[14]. In addition, 
nano-TiO2 has antibacterial and antiviral properties[15-16]. Therefore, nano- $\mathrm{TiO}_{2}$ has a certain hormone effect[17], which can promote the buds regeneration of leaves and the rooting of hypocotyls in tissue culture, and has antibacterial and slow-release properties. In the past, $\mathrm{MS}+0.5 \mathrm{mg} / \mathrm{L} 6-\mathrm{BA}+0.5 \mathrm{mg} / \mathrm{L} \mathrm{NAA}+3 \mathrm{~g} / \mathrm{L}$ activated carbon $+30 \mathrm{~g} / \mathrm{L}$ sodium alginate $+3 \mathrm{~g} / \mathrm{L}$ chlorothalonil were used as the basic endosperm in our research group. It was found that $10 \mathrm{~g} / \mathrm{L}$ nano- $\mathrm{TiO}_{2}$ and $10 \mathrm{~g} / \mathrm{L}$ nano- $-\mathrm{SiO}_{2}$ in the seed coat could significantly promote the germination and seedling formation of synthetic seeds, while the 90 day seedling formation rate of $10 \mathrm{~g} / \mathrm{L}$ nano- $\mathrm{SiO}_{2}$ was the highest, reaching $68.1 \%$. It can be seen that the application of nano- $\mathrm{TiO}_{2}$ in the production of $D$. officinale synthetic seeds may promote the air permeability, antibacterial, germination and growth of the synthetic seeds, which is expected to improve the existing problems in the application of synthetic seeds.

The study reported here was carried out to rapid propagation of $D$. officinale plants via directly protocorms from internodal explants without involving a callus phase. We also demonstrate a method for developing artificial seed that can grow to seedling under in vitro conditions. Moreover, germination of nano- $\mathrm{TiO}_{2}$ synthetic seeds and the physiology of regenerated plants was investigated. These results on artificial seed production can provide a practical means of mass clonal propagation for this precious orchid. In addition, nano- $\mathrm{TiO}_{2}$ encapsulation of $D$. officinale protocorms will be useful for limited breeding methods that lack the appropriate cultivation for conventional sterile micropropagation.

\section{Methods}

\section{Preparation of nano synthetic seeds}

The calcium alginate bulb was used to immerse the protocorm in the synthetic endosperm in the super clean platform. After 5min, the semi gel state of sodium alginate packaging protocorm was dripped into the $2 \% \mathrm{CaCl}_{2}$ solution by suction tube to ensure that each protocorm was wrapped only with a synthetic seed. After $15 \mathrm{~min}$ ion exchange, the seeds were solidified into granules by self action, washed out with distilled water, and put on the filter paper to absorb the surface moisture. Taking MS + $2.0 \mathrm{mg} / \mathrm{L} 6-\mathrm{BA}+0.5 \mathrm{mg} / \mathrm{L} \mathrm{NAA}$ as the basic synthetic endosperm, 3.0\% sodium alginate, $3.0 \%$ cassava starch, $1.0 \%$ water retaining agent, $(0 \%, 1.0 \%, 2.0 \%, 3.0 \%$, 4.0\%, 5.0\%) nano-TiO2 (Hangzhou Wanjing new materials Co. Ltd) as the synthetic seed coat matrix, the material was mixed with it and exchanged with $100 \mathrm{mmol} / \mathrm{L}$ $\mathrm{CaCl}_{2}$ for $15 \mathrm{~min}$. 
Using $\mathrm{MS}+2.0 \mathrm{mg} / \mathrm{L} 6-\mathrm{BA}+0.5 \mathrm{mg} / \mathrm{L} \mathrm{NAA}+0.1 \%$ activated carbon $+2.0 \%$ $-5.0 \%$ sodium alginate $+2.0 \%-3.0 \%$ cassava starch as the basic synthetic endosperm, adding $(0,2.5,5.0,7.5,10.0,12.5,15.0,17.5,20.0,22.5,25.0) \mathrm{g} / \mathrm{L}$ nano $\mathrm{TiO}_{2}$ as the synthetic seed coat matrix. The protocorm was dipped into the synthetic endosperm containing nano-TiO2 in the super clean platform by the drop method. After $5 \mathrm{~min}$, synthetic endosperm of the semi gel state containing the protocorms was dripped into $2.0 \% \mathrm{CaCl}_{2}$ solution with straw to ensure that each protocorm was wrapped only with a synthetic seed and was automatically solidified by $15 \mathrm{~min}$ ion exchange. Took it out and washed it with sterilized redistilled water, put it on the filter paper to absorb the surface water. The nano synthetic seeds of $D$. officinale were obtained.

\section{Germination of nano synthetic seeds}

The seeds were seeded in 1/2MS medium. The germination rate of 30 days and the seedling rate of 60 days were observed. The germination standard was to break through the seed coat by $2 \mathrm{~mm}$, and the seedling standard was that the whole seedlings could completely break through the seed coat and survive on the medium. Each group was treated with 30 synthetic seeds and repeated 3 times. The formula is as follows:

Germination rate $=$ germination number $/$ number of seeds

Seedling rate $=$ number of seedlings $/$ number of seeds

After 6 months of germination of $D$. officinale synthetic seeds, 10 plants were randomly selected for each treatment, and the plant height, stem node number, internode length, leaf number, leaf length and maximum leaf width were measured. The leaf length was the distance from leaf base to leaf tip, and the maximum leaf width was the measured value of shoulder width at the bottom of leaf. The measurement of leaf area is obtained by multiplying the product of leaf length and maximum leaf width by a coefficient of 0.77 . The coefficient comes from the correlation equation between the actual leaf area and the product of leaf length and maximum leaf width, and its correlation coefficient is $r^{2}=0.98$.

\section{Determination of root activity of germinating seedlings}

Take out the root, absorb the water and grind it with $3-4 \mathrm{~mL}$ ethyl acetate and a small amount of quartz sand to get TTF. Transfer the red extraction solution into the test tube, wash the residue with a small amount of ethyl acetate for 2-3 times, transfer them all into the test tube, add ethyl acetate to make the total amount of $10 \mathrm{ml}$, 
compare the color with spectrophotometer at $485 \mathrm{~nm}$ wavelength, read out the optical density with blank as reference, check the standard curve, and calculate the reduction amount of tetrazolium.

The reduction strength of tetrazolium was calculated by taking the data into the following formula.

Reduction strength of tetrazolium $=$ Reduction amount of tetrazolium( $\mu \mathrm{g}) /$ [Root weight $(\mathrm{g}) \times$ Time $(\mathrm{h})]$

\section{Determination of nitrate reductase activity of germinating seedlings}

Take $1.0 \mathrm{~mL}$ of the reaction solution and put it into the centrifuge tube, add $2.0 \mathrm{~mL} 1.0 \%$ sulfanilic acid solution and $2.0 \mathrm{~mL} 0.2 \%$ a-naphthylamine solution, and put it in a water bath at constant $30^{\circ} \mathrm{C}$ for $30 \mathrm{~min}$. At last, the absorbance value was measured at $520 \mathrm{~nm}$, the blank was used as reference, the standard curve was checked, and the $\mathrm{NO}_{2}^{-}$concentration was calculated.

Take the data into the formula below to calculate the activity of nitrate reductase.

Activity of nitrate reductase $[\mu \mathrm{g} /(\mathrm{g} \mathrm{FW} \cdot \mathrm{h})]=\mathrm{C} \times$ Total volume of reaction liquid $(10 \mathrm{ml}) /[$ Reaction time $(0.5 \mathrm{~h}) \times$ Sample weight $(\mathrm{g})]$

Definition: the number of micrograms of $\mathrm{NO}_{2}{ }^{-}$generated by catalysis per hour per gram of fresh weight material is $1 \mathrm{U}$.

\section{Determination of total superoxide dismutase (T-SOD) of germinating seedlings}

The T-SOD test box provided by Nanjing Jiancheng Bioengineering Research Institute was used for determination. After all the reagents were evenly mixed, they were left at room temperature for $10 \mathrm{~min}$, and then the absorbance was measured at $550 \mathrm{~nm}$ wavelength with $1.0 \mathrm{~cm}$ optical diameter cuvette and 0 -redistilled water.

Bring the data into the formula below to find out the total SOD activity.

Total SOD activity $(\mathrm{U} / \mathrm{g} \mathrm{FW})=\left(\mathrm{OD}_{\text {control- }} \mathrm{OD}_{\text {determination }}\right) \times$ Dilution ratio of reaction system $/\left[\mathrm{OD}_{\text {control }} \times 50 \% \times\right.$ Homogenate concentration $(\mathrm{g} / \mathrm{ml})$ ]

Definition: the amount of SOD corresponding to the inhibition rate of $50 \%$ of SOD per gram of tissue in $1.0 \mathrm{ml}$ of reaction solution is a unit of SOD activity (U).

\section{Determination of peroxidase (POD) of germinating seedlings}

The POD test box provided by Nanjing Jiancheng Bioengineering Research Institute was used for determination. After all the reagents were evenly mixed, they were centrifuged at $3500 \mathrm{rpm}$ for $10 \mathrm{~min}$, the supernatant was taken, and the 
absorbance was measured at $420 \mathrm{~nm}$ wavelength with $1 \mathrm{~cm}$ optical diameter cuvette and 0 -redistilled water.

Bring the data into the formula below to calculate the POD activity.

$\mathrm{POD}$ activity $(\mathrm{U} / \mathrm{g} \mathrm{FW})=\left(\mathrm{OD}_{\text {determination }}-\mathrm{OD}_{\text {control }}\right) \times$ Total volume of reaction liquid $(\mathrm{mL}) /[12 \times$ Cuvette optical diameter $(1 \mathrm{~cm}) \times$ Sample size $(\mathrm{mL}) \times$ Reaction time $(30 \mathrm{~min}) \times$ Homogenate concentration $(\mathrm{g} / \mathrm{ml})]$

Definition: at $37{ }^{\circ} \mathrm{C}$, the amount of enzyme catalyzing $1.0 \mu \mathrm{g}$ substrate per gram of tissue per minute is one enzyme activity unit.

\section{Determination of catalase (CAT) activity of germinating seedlings}

The CAT test box provided by Nanjing Jiancheng Bioengineering Research Institute was used for the determination. After all the reagents were well mixed, the absorbance was measured at $405 \mathrm{~nm}$ wavelength with $0.5 \mathrm{~cm}$ optical diameter cuvette and 0-redistilled water.

Bring the data into the formula below to calculate the CAT activity.

$\mathrm{CAT}$ activity $(\mathrm{U} / \mathrm{g} \mathrm{FW})=\left(\mathrm{OD}_{\text {control-OD }} \mathrm{OD}_{\text {determination }}\right) \times 271^{*} /[60 \times$ Sampling quantity $\times$ Homogenate concentration $(\mathrm{g} / \mathrm{ml})$ ]

Note: ${ }^{*} 271$ is the reciprocal of the slope.

Definition: the amount of $1.0 \mu \mathrm{mol} \mathrm{H}_{2} \mathrm{O}_{2}$ decomposed per second per gram of tissue is an activity unit.

\section{Determination of total antioxidant capacity $(\mathrm{T}-\mathrm{AOC})$ of germinating seedlings}

The T-AOC test box provided by Nanjing Jiancheng Bioengineering Research Institute was used for the determination. After all the reagents were evenly mixed, they were placed for 10 minutes. The absorbance was measured at $520 \mathrm{~nm}$ wavelength with $1 \mathrm{~cm}$ optical diameter cuvette and 0 -redistilled water.

Take the data into the formula below to calculate the T-AOC activity.

T-AOC activity $(\mathrm{U} / \mathrm{g} \mathrm{FW})=\left(\mathrm{OD}_{\text {determination- }}-\mathrm{OD}_{\text {control }}\right) \times$ Total amount of reaction liquid $(\mathrm{mL}) /[0.01 \times 30 \times$ Sampling quantity $(\mathrm{mL}) \times$ Homogenate concentration $(\mathrm{g} / \mathrm{ml})]$

Definition: at $37{ }^{\circ} \mathrm{C}$, the absorbance (OD) value of the reaction system is one unit of total antioxidant capacity per gram of tissue per minute, with each increase of 0.01 .

\section{Results}

\section{Nano $\mathrm{TiO}_{2}$ particles}


Through X-ray diffraction analysis, the average grain size of $\mathrm{TiO}_{2}$ particles in the nano- $\mathrm{TiO}_{2}$ sol was $2.6 \mathrm{~nm}$ (see figure 1 and table 1 ); through particle size analyzer analysis, the average effective grain size of $\mathrm{TiO}_{2}$ particles was $0.27 \mu \mathrm{m}$, which showed that the nano- $\mathrm{TiO}_{2}$ sol would agglomerate, because the nano materials were easy to agglomerate (see figure 2); scanning electron microscopy showed that the size of $\mathrm{TiO}_{2}$ particles had reached the nano level, and its distribution in the sol was uniform (see figure 3).

\section{No significant germination rate and seedling rate rising first}

The effects of different concentrations of nano- $\mathrm{TiO}_{2}$ on the germination of synthetic seeds are shown in table 2 and figure 4-5. The results showed that the addition of $0-5.0 \%$ nano- $\mathrm{TiO}_{2}$ had no significant effect on the germination rate of synthetic seeds of $D$. officinale, while the addition of $1.0 \%$ nano- $\mathrm{TiO}_{2}$ could significantly improve the seedling rate of synthetic seeds, up to $(37.78 \pm 1.11) \%$, but with the increase of nano- $\mathrm{TiO}_{2}$ concentration, the seedling rate gradually decreased, which was significantly lower than that of the control group.

\section{Plant growth measurement of germinating seedlings}

See table 3 and figure 6-7 for the growth of germination seedlings of D. officinale after 6 months of inoculation. The results showed that the plant height and the number of stem nodes of the control group were lower. With the addition of nano- $\mathrm{TiO}_{2}$, the plant height and the number of stem nodes of germination seedlings increased. The concentration of nano- $\mathrm{TiO}_{2}$ in the range of $2.5-22.5 \%$ could significantly improve the plant height and the number of stem nodes, and $5.0 \%$ was the best. In addition, it was found that when the concentration of nano- $\mathrm{TiO}_{2}$ was $5.0 \%$, the length of internode, the number of leaves and the area of leaves could be significantly increased.

\section{Root activity rising first and then falling}

It can be seen from figure 8 that the root activity of the nano- $\mathrm{TiO}_{2}$ treatment group increases first and then decreases. When the concentration of nano- $\mathrm{TiO}_{2}$ is $15.0 \mathrm{~g} / \mathrm{L}$, the root activity reaches the maximum value, which is 1.92 times of the control group. Then with the increase of $\mathrm{TiO}_{2}$ concentration, the root activity decreased. 


\section{Increasing activity of nitrate reductase}

It can be seen from figure 9 that the activity of nitrate reductase in the nano- $\mathrm{TiO}_{2}$ treatment group shows a gradual upward trend, which is higher than that in the control group. When the concentration of nano- $\mathrm{TiO}_{2}$ is $22.5 \mathrm{~g} / \mathrm{L}$, the activity of nitrate reductase reaches the maximum value, which is 1.15 times of that in the control group, with a significant difference compared with the control group.

\section{Total SOD activity rising first and then falling}

From figure 10, it can be seen that the total SOD activity of the nano- $\mathrm{TiO}_{2}$ treatment group first increases and then decreases. When the concentration of nano-TiO2 is $17.5 \mathrm{~g} / \mathrm{L}$, the total SOD activity reaches the maximum value, which is 1.36 times of the control group. Then, when the concentration of $\mathrm{TiO}_{2}$ was more than $17.5 \mathrm{~g} / \mathrm{L}$, the total SOD activity decreased gradually. In general, the total SOD activity of nano- $\mathrm{TiO}_{2}$ treatment group was significantly higher than that of the control group.

\section{Increasing activity of POD}

It can be seen from figure 11 that the POD activity of the nano- $\mathrm{TiO}_{2}$ treatment group shows a gradual upward trend, which is larger than that of the control group. When the concentration of nano- $\mathrm{TiO}_{2}$ is $22.5 \mathrm{~g} / \mathrm{L}$, the POD activity reaches the maximum value, which is 1.17 times of the control group. There is a significant difference compared with the control group. In general, the POD activity of the nano- $\mathrm{TiO}_{2}$ treatment group is higher than that of the control group. When the concentration of nano- $\mathrm{TiO}_{2}$ is more than $10.0 \mathrm{~g} / \mathrm{L}$, there are significant difference compared with the control group.

\section{CAT activity rising first and then falling}

From figure 12, it can be seen that the CAT activity of the nano $\mathrm{TiO}_{2}$ treatment group shows a gradual upward trend, which is higher than that of the control group. When the concentrations of nano $\mathrm{TiO}_{2}$ are $10 \mathrm{~g} / \mathrm{L}$ and $12.5 \mathrm{~g} / \mathrm{L}$, the CAT activity reaches the maximum value, which is 5.66 and 5.78 times of that of the control group, respectively. There are significant differences compared with the control group. However, when the nano- $\mathrm{TiO}_{2}$ is more than $12.5 \mathrm{~g} / \mathrm{L}$, the CAT activity decreases gradually. In general, the CAT activity of nano- $\mathrm{TiO}_{2}$ treatment group is higher than that of the control group. When the concentration of nano- $\mathrm{TiO}_{2}$ is more than $2.5 \mathrm{~g} / \mathrm{L}$, there are significant differences compared with the control group. 


\section{Increasing activity of T-AOC}

It can be seen from figure 13 that the T-AOC activity of the nano- $\mathrm{TiO} 2$ treatment group shows a gradual upward trend, and the T-AOC activity is higher than that of the control group (except for the concentration of $2.5 \mathrm{~g} / \mathrm{L}$, which may be a problem of error). When the concentration of nano- $\mathrm{TiO}_{2}$ is $22.5 \mathrm{~g} / \mathrm{L}$, the $\mathrm{T}-\mathrm{AOC}$ activity reaches the maximum value, which is 2.74 times of the control group, with a significant difference compared with the control group.

\section{Statistical analysis}

The experimental data were expressed by mean \pm SD. The statistical analysis method was IBM SPSS statistics v19.0 and one way ANOVA (one way analysis of variance). The significance of the differences between groups was tested by Duncan test.

\section{Discussion}

Through the analysis of X-ray, particle size analyzer and scanning electron microscope, it can be seen that the size of $\mathrm{TiO}_{2}$ particles in the sol has reached nanometer level, the average grain size is $2.6 \mathrm{~nm}$, and it is evenly distributed in the sol, but agglomeration phenomenon appears, which may be that nano materials are prone to agglomeration. The results showed that the addition of $0 \%-5.0 \%$ nano- $\mathrm{TiO}_{2}$ had no significant effect on the germination rate of $D$. officinale aritificial seeds, but the addition of $1.0 \%$ nano- $\mathrm{TiO}_{2}$ could significantly improve the rate of seedling, which may be due to the application of its energy conversion performance, the increase of seed activity, and the increase of enzyme activity in the seeds of D. officinale, so as to promote the seedling of $D$. officinale seeds. However, with the increase of $\mathrm{TiO}_{2}$ concentration, the germination of $D$. officinale may be inhibited. The bacteria-existing germination of synthetic seeds is the key to their application. In this experiment, some researches were carried out (sowing on outdoor agar gel system), but synthetic seeds withered with time and failed to germinate, so this needs further study.

The results showed that the plant height, stem node number, internode length, leaf number and leaf area of $D$. officinale germination seedlings were comprehensively investigated, $5.0 \%$ nano- $\mathrm{TiO}_{2}$ had a significant effect on the growth of the germination seedlings of $D$. officinale. However, with the increase of $\mathrm{TiO}_{2}$ concentration, the number of stem nodes, the length of internode, the number of 
leaves, the area of leaves and so on were inhibited, and then the growth of D. officinale germination seedlings was inhibited.

Root activity index is an important target to reflect root growth and activity level. It was reported that the length of Lemna minor roots decreased by $99 \%$ when exposure to nano $\mathrm{TiO}_{2}[18]$. In this study, with the increase of nano- $\mathrm{TiO}_{2}$, the root activity of $D$. officinale germination seedlings showed an upward trend. When the concentration of nano- $\mathrm{TiO}_{2}$ was $15.0 \mathrm{~g} / \mathrm{L}$, the root activity reached the maximum. Nano- $\mathrm{TiO}_{2}$ semiconductor sol can promote the ability of plants to absorb water, which may be related to the increase of stomatal conductance and transpiration rate of leaf cells.

Nitrate reductase is the rate-limiting enzyme in the process of nitrate assimilation in plants, which plays an important role in nitrogen metabolism. The activity of nitrate reductase in plants directly affects the utilization of inorganic nitrogen in soil, thus affecting the quality and yield of plants [19-20]. The results showed that the addition of nano- $\mathrm{TiO}_{2}$ could promote the increase of nitrate and nitrite content in the cells of D. officinale germination seedlings, and the $\mathrm{NO}$ content of $22.5 \mathrm{~g} / \mathrm{L}$ nano- $\mathrm{TiO}_{2}$ group is the highest. When the concentration of nano- $\mathrm{TiO}_{2}$ was more than $22.5 \mathrm{~g} / \mathrm{L}$, the activity of nitrate reductase decreased gradually.

SOD enzyme is an enzyme containing metal cofactors, which is the first to react with $\mathrm{O}^{2-}$, and plays an important role in the process of disproportionation of $\mathrm{O}^{2-}$ to generate $\mathrm{H}_{2} \mathrm{O}_{2}$ and $\mathrm{O}_{2}[21]$. Therefore, the induction of SOD activity indicates that a large amount of $\mathrm{O}^{2-}$ is produced in the plant, which makes the plant in an oxidative stress state. When nano materials contact with organisms, cells will generate a lot of reactive oxygen [22]. In this study, it was found that at the concentration of $17.5 \mathrm{~g} / \mathrm{L}$, nano- $\mathrm{TiO}_{2}$ increased the content of $\mathrm{O}^{2-}$ in the germinating seedlings of $D$. officinale synthetic seeds, made the plants in the state of oxidation stress, thus promoted the activity of SOD enzyme, and eliminated excessive $\mathrm{O}^{2-}$. With the concentration of nano- $\mathrm{TiO}_{2}>17.5 \mathrm{~g} / \mathrm{L}$, the activity of total SOD decreased gradually. SOD itself may be affected by nano- $\mathrm{TiO}_{2}$ particles, so the SOD activity decreases with the increase of nano- $\mathrm{TiO}_{2}$ concentration [23-25].

POD enzyme can remove the $\mathrm{H}_{2} \mathrm{O}_{2}$ produced in plants, reduce the concentration of $\mathrm{H}_{2} \mathrm{O}_{2}$ in plants, prevent membrane lipid peroxidation, and protect the body from the damage of active oxygen substances. Therefore, the induction of POD enzyme activity indicates that a large amount of $\mathrm{H}_{2} \mathrm{O}_{2}$ is produced in the plant, which makes the plant in an oxidative stress state. In this study, it was found that with the increase 
of the concentration of nano- $\mathrm{TiO}_{2}$, the activity of POD enzyme increased significantly, and the activity of POD enzyme in the treatment group was higher than that in the control group, which indicated that the activity of POD enzyme in the germination seedlings of $D$. officinale treated with nano- $\mathrm{TiO}_{2}$ could better resist oxidative damage. This result is consistent with the Tian's study [25].

CAT enzyme can remove $\mathrm{H}_{2} \mathrm{O}_{2}$ produced in plants and prevent membrane lipid peroxidation. Therefore, the induction of CAT enzyme activity indicates that a large amount of $\mathrm{H}_{2} \mathrm{O}_{2}$ is produced in plants, which makes plants in an oxidation stress state. In this study, the activity of CAT enzyme in the treatment group of nano- $\mathrm{TiO}_{2}$ firstly increased and then decreased, which showed that when the concentration of nano- $\mathrm{TiO}_{2}$ was more than $2.5 \mathrm{~g} / \mathrm{L}$ and less than $15.0 \mathrm{~g} / \mathrm{L}$, the content of $\mathrm{H}_{2} \mathrm{O}_{2}$ in the germination seedling of $D$. officinale increased gradually, which promoted the mass synthesis of CAT enzyme, eliminated the excessive $\mathrm{H}_{2} \mathrm{O}_{2}$ and prevented the oxidative damage; while with the concentration of nano- $\mathrm{TiO}_{2}$ more than $12.5 \mathrm{~g} / \mathrm{L}$, the activity of CAT enzyme in the germination seedling of $D$. officinale is decreasing. In general, the CAT activity of $D$. officinale germination seedling treated with nano- $\mathrm{TiO}_{2}$ was higher than that without nano- $\mathrm{TiO}_{2}$. With the increase of the amount of nano-TiO2, Tian et al found that the CAT enzyme activity showed an overall upward trend, which was the difference of this research results due to different plant species and nano- $\mathrm{TiO}_{2}$ phase types[25].

T-AOC is an index to measure the total antioxidant capacity of the body[26]. Its level represents the comprehensive level of antioxidant capacity of body fluid, cell, tissue enzyme system and tissue non-enzyme system[27]. The results showed that the T-AOC activity of germination seedlings of $D$. officinale was significantly higher than that of the group without nano- $\mathrm{TiO}_{2}$ when nano- $\mathrm{TiO}_{2}$ was more than $2.5 \mathrm{~g} / \mathrm{L}$, indicating that the antioxidant function of germination seedlings treated with nano- $\mathrm{TiO}_{2}$ was increased, and increased with the increase of nano- $\mathrm{TiO}_{2}$.

To sum up, adding appropriate nano- $\mathrm{TiO}_{2}$ into the synthetic endosperm is beneficial to the growth and development of germination seedlings, and improves the root activity, nitrate reductase activity and antioxidant system activity, which provides a basis for the improvement of the preparation process and the practical production of D. officinale synthetic seeds.

\section{Availability of data and materials}

The authors declare that the materials and data are available to the readers, and 
all conclusions made in this manuscript are based on the data which are all presented and shown in this paper.

\section{References}

1. Ghosh B, Sen S. Plant regeneration from alginate encapsulated somatic embryos of Asparagus cooperi baker. Plant Cell Rep 1994; 9:189-194.

2. Redenbaugh K, Paasch BD, Nichol JM, et al. Somatic seeds: encapsulation of asexual plant embryos. Nature Biotechnology. 1986; 4: 797-801.

3. Bapat VA, Rao PS. Sandalwood plantlets from "synthetic seeds". Plant Cell Rep. 1988; 7: 434-436.

4. Fowke LC, Attree SM, Pomeroy MK. Production of vigorous desiccation-tolerant white spruce [Picea glauca (Moench) Voss.] synthetic seeds in a bioreactor. Plant Cell Rep. 1994;13:601-606.

5. Onay A, Jeffree CE, Yeoman MM. Plant regeneration from encapsulated embryoids and an embryogenic mass of pistachio, Pistachio vera L. Plant Cell Rep. 1996; 15: 723-726.

6. Courtenay Willis, William J. Mitsch. Effects of hydrology and nutrients on seedling emergence and biomass of aquatic macrophytes from natural and synthetic seed banks. Ecological Engineering. 1995;4: 65-76.

7. Ipekci Z, Gozukirmizi N. Direct somatic embryogenesis and synthetic seed production from Paulownia elongata. Plant Cell Rep. 2003; 22:16-24.

8. Teixeira da Silva JA1, Zeng S, Galdiano RF Jr, et al. In vitro conservation of Dendrobium germplasm. Plant Cell Rep. 2014; 33:1413-23.

9. Zhang M, Cheng J, Sun Z, et al. Protective Effects of Carbon Dots Derived from Phellodendri Chinensis Cortex Carbonisata against Deinagkistrodon acutus Venom-Induced Acute Kidney Injury. Nanoscale Res Lett. 2019;14(1):377.

10. Cao D, Gong S, Shu X, et al. Preparation of ZnO Nanoparticles with High Dispersibility Based on Oriented Attachment (OA) Process. Nanoscale Res Lett. 2019;14(1):210.

11. Singh J, Lee BK. Influence of nano-TiO2 particles on the bioaccumulation of $\mathrm{Cd}$ in soybean plants (Glycine max): A possible mechanism for the removal of $\mathrm{Cd}$ from the contaminated soil. J Environ Manage. 2016; 170:88-96.

12. Bakshi M, Liné C, Bedolla DE, et al. Assessing the impacts of sewage sludge amendment containing nano-TiO2 on tomato plants: A life cycle study. J Hazard Mater. 2019; 369:191-198.

13. Tan W, Du W, Barrios AC, et al. Surface coating changes the physiological and biochemical impacts of nano-TiO2 in basil (Ocimum basilicum) plants. Environ Pollut. 2017; 222: 64-72. 
14. Wenjing Zhang, Zhi-Ping Zhang, Xian-En Zhang, et al. Reaction inside a viral protein nanocage: Mineralization on a nanoparticle seed after encapsulation via self-assembly. Nano Research. 2017; 10:3285-3294.

15. Joost U, Juganson K, Visnapuu M, et al. Photocatalytic antibacterial activity of nano-TiO2 (anatase)-based thin films: effects on Escherichia coli cells and fatty acids.J Photochem Photobiol B. 2015; 142:178-85.

16. Yang H, Wang Y, Xue X. Influences of glycerol as an efficient doping agent on crystal structure and antibacterial activity of B-TiO2 nano-materials. Colloids Surf B Biointerfaces.2014; 122:701-708.

17. Jia F, Sun Z, Yan X, et al. Effect of pubertal nano-TiO2 exposure on testosterone synthesis and spermatogenesis in mice. Arch Toxicol. 2014; 88:781-8.

18. Dolenc Koce J. Effects of exposure to nano and bulk sized $\mathrm{TiO} 2$ and $\mathrm{CuO}$ in Lemna minor. Plant Physiol Biochem. 2017; 119:43-49.

19. Das P, Barua S, Sarkar S, et al. Plant extract-mediated green silver nanoparticles: Efficacy as soil conditioner and plant growth promoter.J Hazard Mater. 2018; 346:62-72.

20. Lang CP, Merkt N, Zörb C. Different nitrogen (N) forms affect responses to N form and $\mathrm{N}$ supply of rootstocks and grafted grapevines. Plant Sci. 2018; 277:311-321.

21. Zheng W, Zou HF, Lv SW, et al. The effect of nano-TiO2 photocatalysis on the antioxidant activities of $\mathrm{Cu}, \mathrm{Zn}-\mathrm{SOD}$ at physiological $\mathrm{pH}$. J Photochem Photobiol B. 2017 ; 174: 251-260.

22. Zhang $\mathrm{H}, \mathrm{He} \mathrm{X}$, Zhang $\mathrm{Z}$, et al. Nano-CeO2 exhibits adverse effects at environmental relevant concentrations. Environ Sci Technol. 2011; 45(8): 3725-30.

23. Silva LND, Pessoa MTC, Alves SLG, et al. Differences of lipid membrane modulation and oxidative stress by digoxin and 21-benzylidene digoxin. Exp Cell Res. 2017; 359:291-298.

24. Sun Y, Sun P, Wang C, et al. Growth, physiological function, and antioxidant defense system responses of Lemna minor L. to decabromodiphenyl ether (BDE-209) induced phytotoxicity. Plant Physiol Biochem. 2019; 139:113-120.

25. Tian F, Chen W, Wu C, et al. Preservation of Ginkgo biloba seeds by coating with chitosan/nano-TiO2 and chitosan/nano-SiO2films. Int J Biol Macromol. 2019; 126:917-925.

26. Chen J, Zhao H, Yang Y, et al. Lipid-lowering and antioxidant activities of Jiang-Zhi-Ning in Traditional Chinese Medicine. J Ethnopharmacol. 2011;134: 919-30.

27. Qin F, Shen T, Cao $\mathrm{H}$, et al. CeO2NPs relieve radiofrequency radiation, improve testosterone synthesis, and clock gene expression in Leydig cells by enhancing antioxidation. Int J Nanomedicine. 2019; 14: 4601-4611. 


\section{Acknowledgements}

I would like to express my gratitude to the financial support from the National Sci-tech Support Plan (2011BAI01B02), National Natural Science Foundation of China (81001601) and Natural Science Foundation of Guangdong Province (9451040701003).

\section{Funding}

This work was funded by the National Sci-tech Support Plan (2011BAI01B02), National Natural Science Foundation of China (81001601) and Natural Science Foundation of Guangdong Province (9451040701003).

\section{Author information}

\section{Affiliations}

Department of Chemistry, The University of Hong Kong, Hongkong, China.

Jiemin Guan

Mathematical Engineering Academy of Chinese Medicine, Guangzhou University of Chinese Medicine, Guangdong, China.

Jiemin Guan \& Xiaoping Lai

Tang Guan Food Trading Co., Ltd., Guangzhou, China.

Jiemin Guan, Jiexian Guan \& Baohua Li

School of Chinese Materia Medica, Guangzhou University of Chinese Medicine, Guangzhou, China.

Xiaoping Lai, Guifang Zhang \& Shijie Li

\section{Contributions}

JG, GZ and XL prepared the materials. JG, GZ and SL carried out the experiment. JG and GZ contributed to the result analysis. JG, JG and BL wrote the manuscript. All authors read and approved the final manuscript.

\section{Corresponding author}

Correspondence to Jiemin Guan.

\section{Ethics declarations}

\section{Competing Interests}

The authors declare that they have no competing interests. 


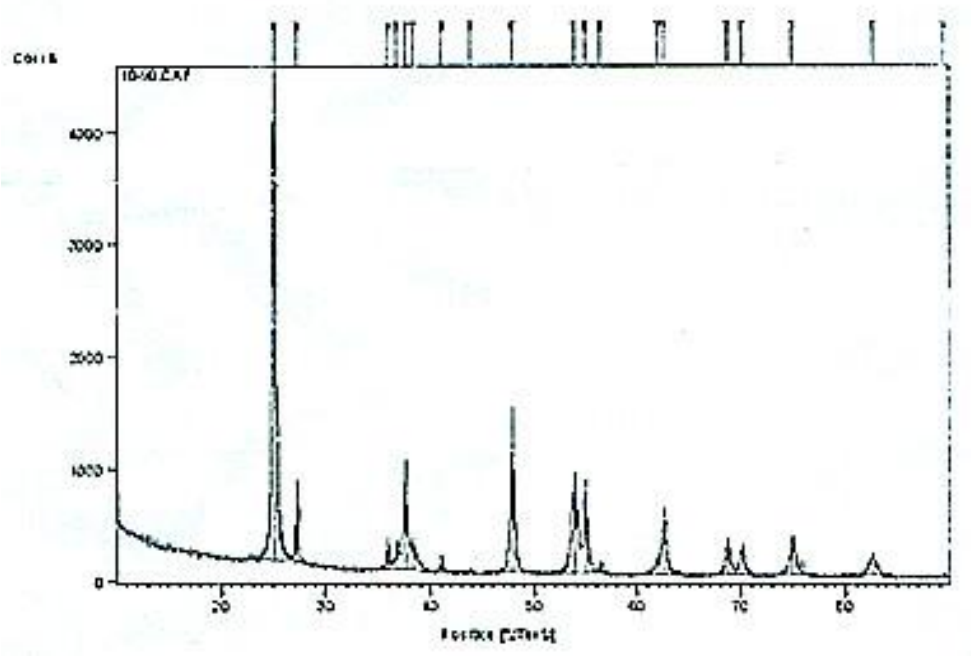

Figure 1 Determination of average grain size of nano- $\mathrm{TiO}_{2}$ sol by X-ray diffraction analysis (peak: $2.6 \mathrm{~nm}$ )

Table 1 Peak value of average grain size of nano $\mathrm{TiO}_{2}$ sol determined by X-ray diffraction analysis

\begin{tabular}{cccccc}
\hline $\begin{array}{c}\text { FWHM } \\
{\left[{ }^{\circ} \text { Th. }\right]}\end{array}$ & $\begin{array}{c}\text { Pos. } \\
{\left[{ }^{\circ} 2 \text { Th. }\right]}\end{array}$ & $\begin{array}{c}\text { Height } \\
{[\mathrm{cts}]}\end{array}$ & $\begin{array}{c}\text { d-spacing } \\
{[\mathrm{A}]}\end{array}$ & $\begin{array}{c}\text { Rel. Int. } \\
{[\%]}\end{array}$ & $\begin{array}{c}\text { Area } \\
{[\text { cts* } 2 \text { Th. }]^{*}}\end{array}$ \\
\hline 0.4039 & 25.1711 & 5590.62 & 3.53515 & 100.00 & 2257.79 \\
0.3004 & 27.3031 & 735.11 & 3.26375 & 13.15 & 220.84 \\
0.2775 & 35.9507 & 303.74 & 2.49605 & 5.43 & 84.28 \\
0.4766 & 36.8526 & 271.51 & 2.43700 & 4.86 & 129.89 \\
0.4009 & 37.6906 & 977.89 & 2.38472 & 17.49 & 392.00 \\
0.7772 & 38.4078 & 260.43 & 2.34182 & 4.66 & 202.41 \\
0.2564 & 41.1188 & 170.77 & 2.19347 & 3.05 & 43.79 \\
0.2133 & 43.9004 & 55.15 & 2.06072 & 0.99 & 11.76 \\
0.4340 & 47.9097 & 1483.70 & 1.89721 & 26.54 & 643.98 \\
0.6237 & 53.8772 & 893.66 & 1.70031 & 15.99 & 557.41 \\
0.4741 & 54.9274 & 833.29 & 1.67025 & 14.91 & 395.08 \\
0.2424 & 56.4991 & 124.31 & 1.62746 & 2.22 & 30.18 \\
0.9296 & 62.0668 & 133.05 & 1.49417 & 2.38 & 123.68 \\
0.4855 & 62.5994 & 610.09 & 1.48273 & 10.91 & 286.21 \\
0.5342 & 68.7595 & 328.53 & 1.36414 & 5.88 & 170.51 \\
0.5569 & 70.1220 & 280.69 & 1.34094 & 5.02 & 156.32 \\
0.7677 & 74.9733 & 362.88 & 1.26574 & 6.49 & 278.58 \\
0.9850 & 82.6136 & 203.74 & 1.16696 & 3.64 & 200.69 \\
0.3264 & 89.4152 & 15.38 & 1.09497 & 0.28 & 10.04 \\
\hline
\end{tabular}




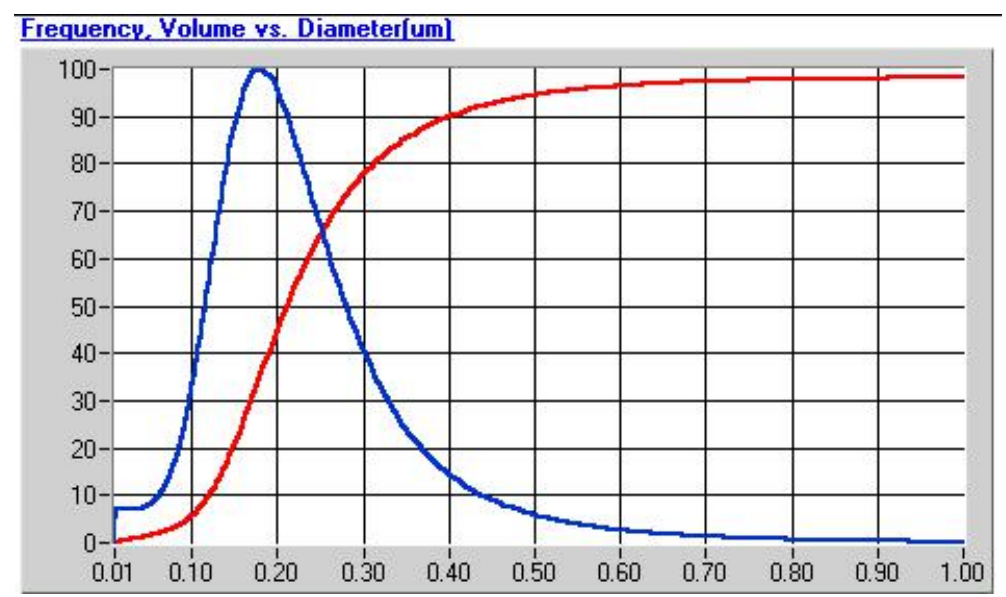

Figure 2 Particle size analysis results of nano $\mathrm{TiO}_{2}$ sol

Note: The blue line is the differential distribution curve and the red line is the cumulative distribution curve.
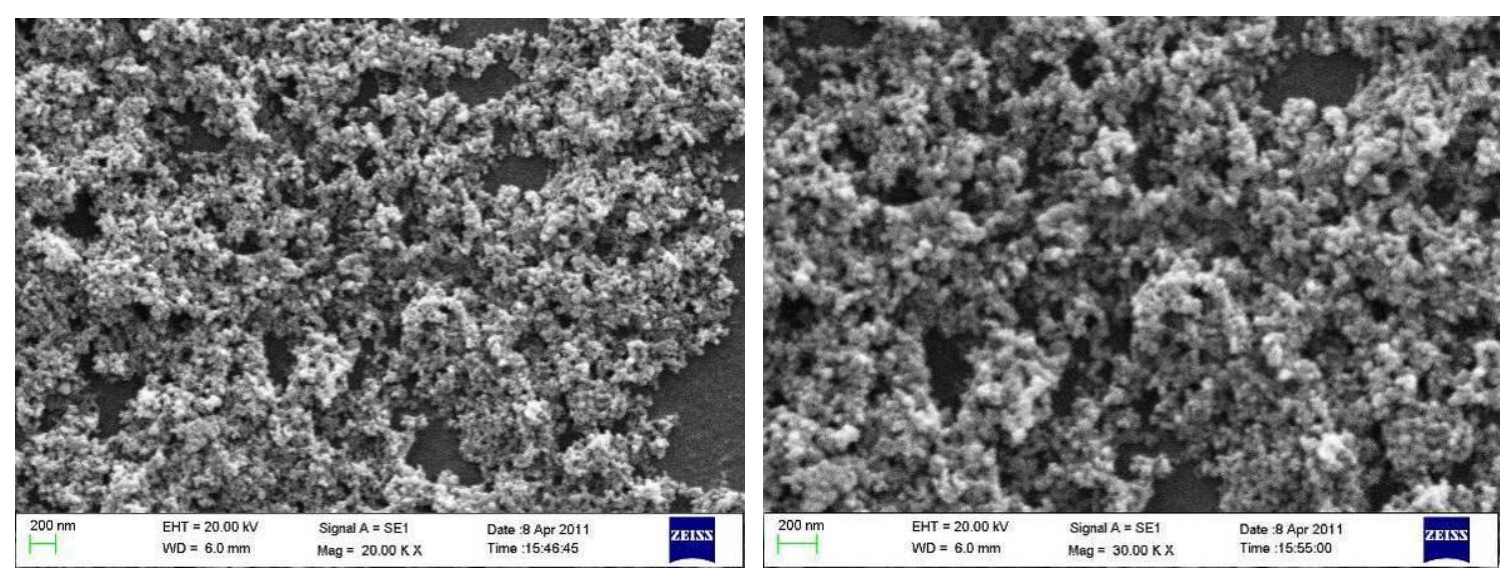

Figure 3 Nano $\mathrm{TiO}_{2}$ sol under scanning electron microscope (A: 20000 times; B: 30000 times)

Table 2 Effect of different concentration of nano- $\mathrm{TiO}_{2}$ on the germination of synthetic seeds $(\%)$

\begin{tabular}{cccc}
\hline Nano- $^{-} \mathrm{TiO}_{2}(\%)$ & Number & Germination rate & Seedling rate \\
\hline 0 & 90 & $66.67 \pm 10.18^{\mathrm{a}}$ & $31.11 \pm 2.94^{\mathrm{bc}}$ \\
1.0 & 90 & $70.00 \pm 3.85^{\mathrm{a}}$ & $37.78 \pm 1.11^{\mathrm{c}}$ \\
2.0 & 90 & $52.22 \pm 12.81^{\mathrm{a}}$ & $30.00 \pm 3.85^{\mathrm{abc}}$ \\
3.0 & 90 & $50.00 \pm 20.09^{\mathrm{a}}$ & $26.67 \pm 6.67^{\mathrm{abc}}$ \\
4.0 & 90 & $57.78 \pm 19.28^{\mathrm{a}}$ & $22.22 \pm 4.45^{\mathrm{ab}}$ \\
5.0 & 90 & $66.67 \pm 6.94^{\mathrm{a}}$ & $18.89 \pm 2.22^{\mathrm{a}}$ \\
\hline
\end{tabular}



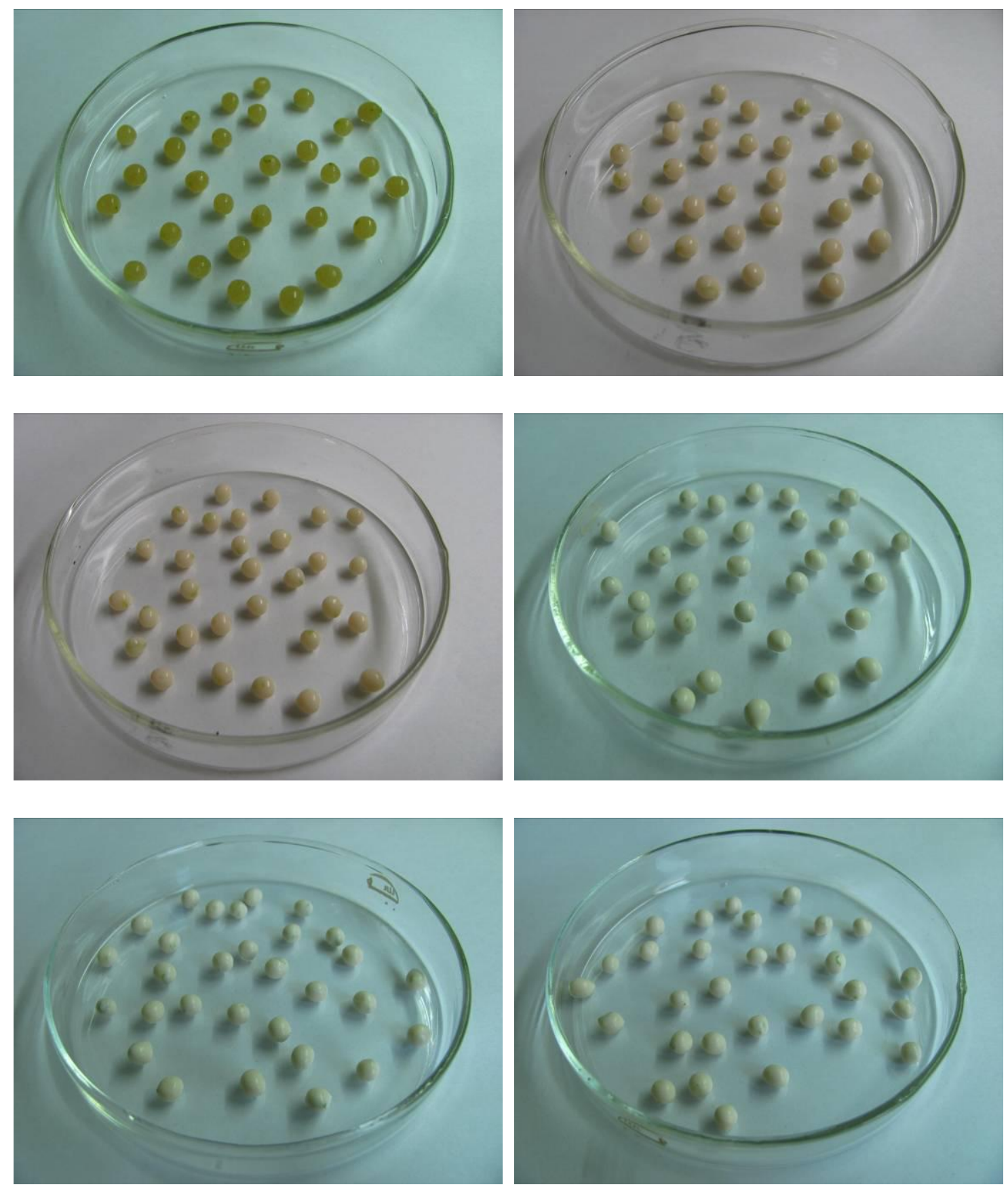

Figure 4 Synthetic seeds (diameter $=0.5 \mathrm{~cm}$ ) of $D$. officinale prepared by adding different concentrations of nano- $\mathrm{TiO}_{2}$

(A - F: 0, 1.0, 2.0, 3.0, 4.0, 5.0\% nano- $\mathrm{TiO}_{2}$ concentration respectively), $\mathrm{MS}+2.0 \mathrm{mg} / \mathrm{L}$ $6-\mathrm{BA}+0.5 \mathrm{mg} / \mathrm{L} \mathrm{NAA}+3.0 \%$ sodium alginate $+3.0 \%$ cassava starch $+1.0 \%$ water retaining agent for synthetic endosperm 

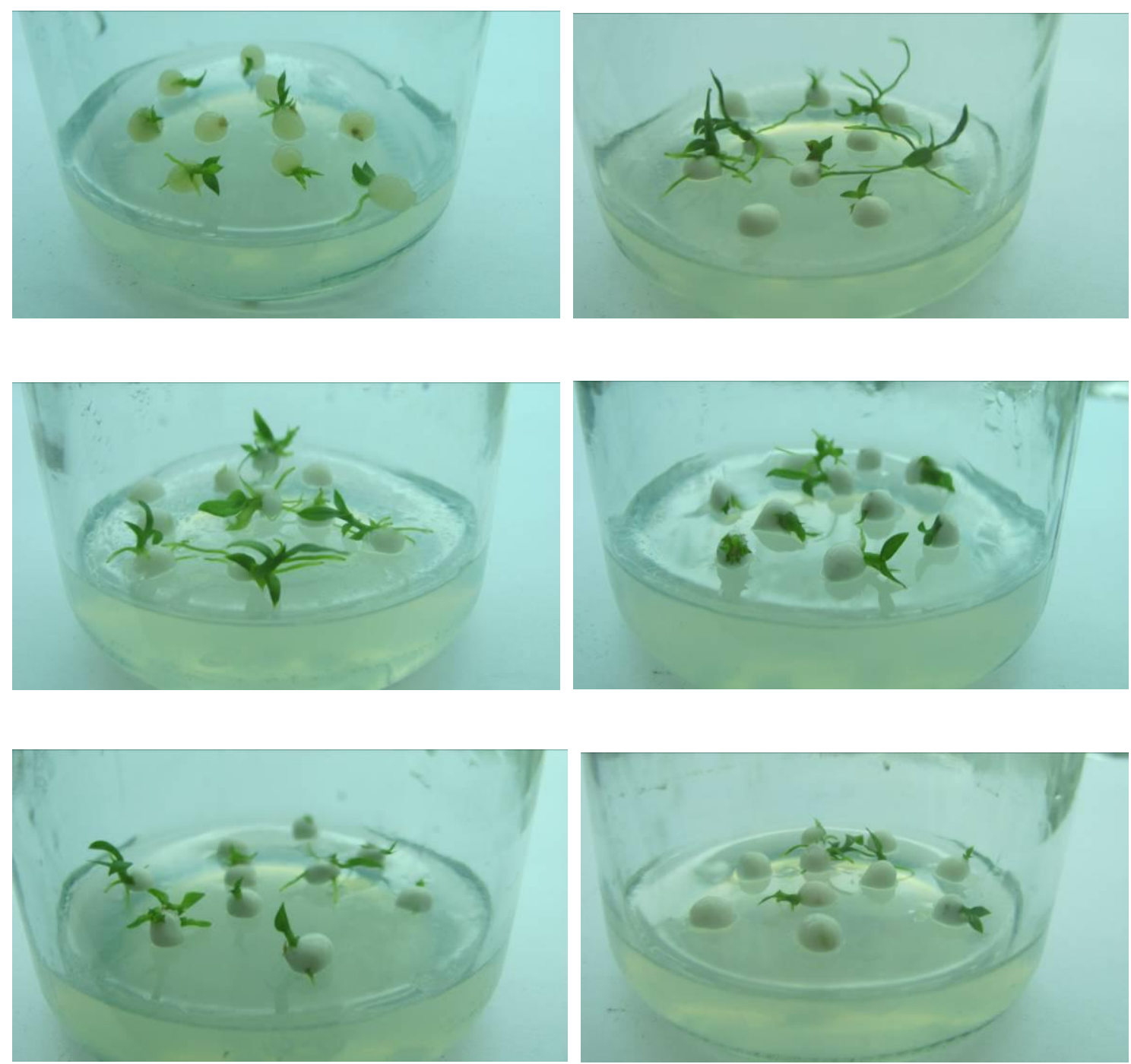

Figure 5 Effect of different concentration of nano- $\mathrm{TiO}_{2}$ on the 60 days seedling formation of $D$. officinale synthetic seeds (diameter $=0.5 \mathrm{~cm}$ ) (A - F: 0, 1.0, 2.0, 3.0, 4.0, 5.0\% nano- $\mathrm{TiO}_{2}$ concentration respectively) 
Table 3 Growth of germination seedlings of $D$. officinale synthetic seeds after 6 months of inoculation

\begin{tabular}{|c|c|c|c|c|c|c|}
\hline $\begin{array}{l}\text { Nano-Ti } \\
\mathrm{O}_{2}(\mathrm{~g} / \mathrm{L})\end{array}$ & $\begin{array}{c}\text { Num } \\
\text { ber }\end{array}$ & $\begin{array}{l}\text { Plant height } \\
(\mathrm{cm})\end{array}$ & $\begin{array}{l}\text { Number of } \\
\text { stem nodes }\end{array}$ & $\begin{array}{c}\text { Length of } \\
\text { internode }(\mathrm{cm})\end{array}$ & $\begin{array}{l}\text { Number } \\
\text { of leaves }\end{array}$ & $\begin{array}{c}\text { Area of } \\
\text { leaves }\end{array}$ \\
\hline 0 & 10 & $1.53 \pm 0.31^{\mathrm{a}}$ & $\begin{array}{c}2.00 \pm \\
0.47^{\mathrm{a}}\end{array}$ & $0.30 \pm 0.08^{\mathrm{bc}}$ & $\begin{array}{l}5.00 \pm \\
0.94^{\mathrm{abc}}\end{array}$ & $\begin{array}{l}0.99 \pm \\
0.03^{\mathrm{abc}}\end{array}$ \\
\hline 2.5 & 10 & $2.13 \pm 0.50^{b}$ & $\begin{array}{l}3.80 \pm \\
0.92^{\text {def }}\end{array}$ & $0.36 \pm 0.08^{c}$ & $\begin{array}{l}5.40 \pm \\
0.84^{\mathrm{abc}}\end{array}$ & $\begin{array}{c}0.16 \pm \\
0.05^{\mathrm{e}}\end{array}$ \\
\hline 5.0 & 10 & $2.58 \pm 0.40^{b}$ & $\begin{array}{l}4.50 \pm \\
1.08^{\mathrm{f}}\end{array}$ & $0.34 \pm 0.11^{\mathrm{c}}$ & $\begin{array}{r}5.80 \pm \\
0.79^{c}\end{array}$ & $\begin{array}{l}0.14 \pm \\
0.06^{\text {de }}\end{array}$ \\
\hline 7.5 & 10 & $2.12 \pm 0.38^{\mathrm{b}}$ & $\begin{array}{l}3.90 \pm \\
0.88^{\mathrm{ef}}\end{array}$ & $0.25 \pm 0.07^{\mathrm{b}}$ & $\begin{array}{l}5.10 \pm \\
0.57^{\mathrm{abc}}\end{array}$ & $\begin{array}{l}0.08 \pm \\
0.02^{\mathrm{ab}}\end{array}$ \\
\hline 10.0 & 10 & $1.13 \pm 0.23^{\mathrm{a}}$ & $\begin{array}{r}2.20 \pm \\
0.63^{\mathrm{ab}}\end{array}$ & $0.16 \pm 0.05^{\mathrm{a}}$ & $\begin{array}{r}4.50 \pm \\
0.85^{\mathrm{a}}\end{array}$ & $\begin{array}{r}0.06 \pm \\
0.03^{\mathrm{a}}\end{array}$ \\
\hline 12.5 & 10 & $2.60 \pm 0.77^{\mathrm{b}}$ & $\begin{array}{l}3.90 \pm \\
1.37^{\mathrm{ef}}\end{array}$ & $0.31 \pm 0.11^{\mathrm{bc}}$ & $\begin{array}{l}5.50 \pm \\
1.35^{\mathrm{bc}}\end{array}$ & $\begin{array}{l}0.13 \pm \\
0.05^{\text {cde }}\end{array}$ \\
\hline 15.0 & 10 & $2.28 \pm 0.56^{b}$ & $\begin{array}{l}3.20 \pm \\
0.92^{\text {cde }}\end{array}$ & $0.29 \pm 0.07^{\mathrm{bc}}$ & $\begin{array}{l}4.80 \pm \\
0.63^{\mathrm{ab}}\end{array}$ & $\begin{array}{l}0.11 \pm \\
0.03^{\text {bcd }}\end{array}$ \\
\hline 17.5 & 10 & $2.55 \pm 0.41^{\mathrm{b}}$ & $\begin{array}{l}3.70 \pm \\
0.82^{\text {def }}\end{array}$ & $0.32 \pm 0.08^{\mathrm{bc}}$ & $\begin{array}{l}5.00 \pm \\
0.82^{\mathrm{abc}}\end{array}$ & $\begin{array}{c}0.16 \pm \\
0.05^{\mathrm{e}}\end{array}$ \\
\hline 20.0 & 10 & $2.16 \pm 0.52^{b}$ & $\begin{array}{l}3.00 \pm \\
0.67^{\text {bcd }}\end{array}$ & $0.24 \pm 0.05^{\mathrm{ab}}$ & $\begin{array}{l}5.00 \pm \\
0.94^{\mathrm{abc}}\end{array}$ & $\begin{array}{l}0.11 \pm \\
0.03^{\text {bcd }}\end{array}$ \\
\hline 22.5 & 10 & $2.31 \pm 0.63^{\mathrm{b}}$ & $\begin{array}{l}3.40 \pm \\
0.84^{\text {cde }}\end{array}$ & $0.35 \pm 0.13^{\mathrm{c}}$ & $\begin{array}{l}5.00 \pm \\
0.82^{\mathrm{abc}}\end{array}$ & $\begin{array}{l}0.12 \pm \\
0.05^{\text {cde }}\end{array}$ \\
\hline 25.0 & 10 & $2.14 \pm 0.28^{b}$ & $\begin{array}{l}2.60 \pm \\
0.70^{\mathrm{abc}}\end{array}$ & $0.24 \pm 0.08^{\mathrm{ab}}$ & $\begin{array}{l}4.80 \pm \\
0.79^{\mathrm{ab}}\end{array}$ & $\begin{array}{l}0.09 \pm \\
0.01^{\mathrm{abc}}\end{array}$ \\
\hline
\end{tabular}



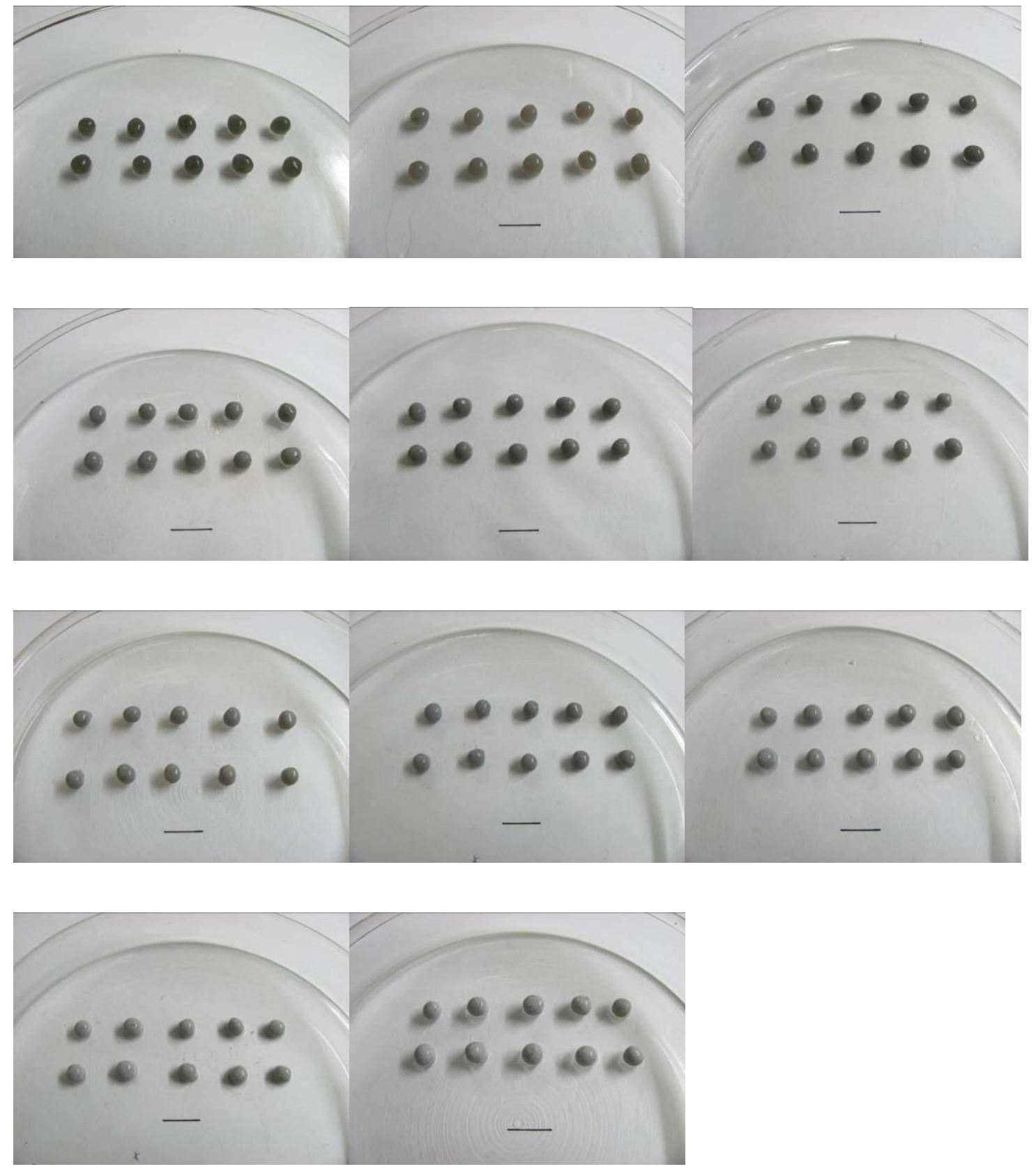

Figure 6 Nano synthetic seeds of $D$. officinale: take MS $+2.0 \mathrm{mg} / \mathrm{L} 6-\mathrm{BA}+0.5 \mathrm{mg} / \mathrm{L}$ NAA $+0.1 \%$ active carbon $+2.0 \%-5.0 \%$ sodium alginate $+2.0 \%-3.0 \%$ cassava starch as basic synthetic endosperm, and add $(0,2.5,5.0,7.5,10,12.5,15,17.5,20,22.5,25) \mathrm{g} / \mathrm{L}$ nano- $\mathrm{TiO}_{2}(\mathrm{~A}-\mathrm{K})$ respectively. The horizontal line represents $1 \mathrm{~cm}$ length. 

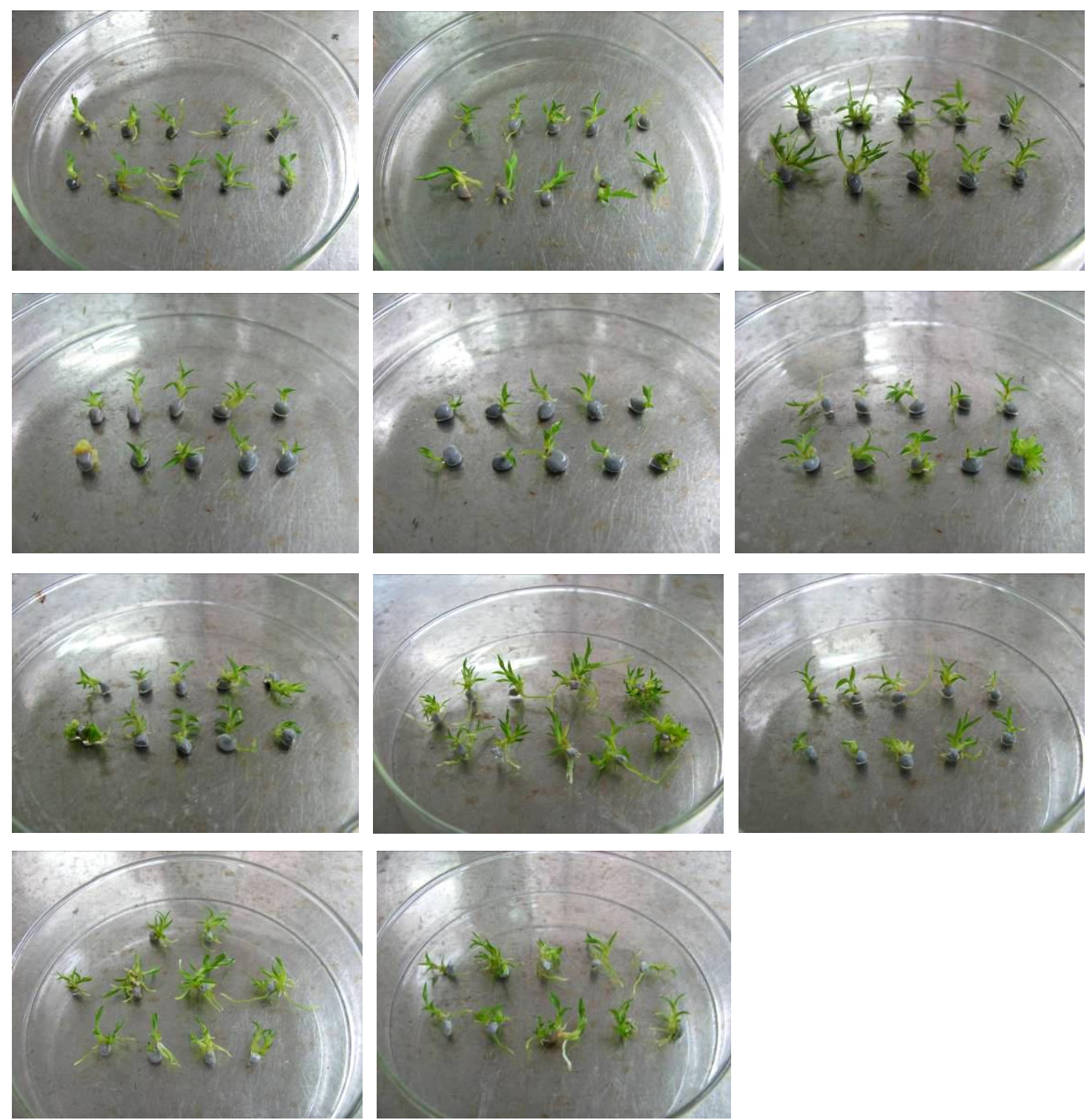

Figure 7 Effects of different concentrations of nano- $\mathrm{TiO}_{2}$ on the seedling formation of D. officinale synthetic seeds (diameter $=0.5 \mathrm{~cm}$ ) in $60 \mathrm{~d}$

(A - F: adding nano- $\mathrm{TiO}_{2}$ concentration of $0,2.5,5.0,7.5,10,12.5,15,17.5,20,22.5$, $25 \mathrm{~g} / \mathrm{L})$, basic synthetic endosperm of $\mathrm{MS}+2.0 \mathrm{mg} / \mathrm{L} 6-\mathrm{BA}+0.5 \mathrm{mg} / \mathrm{L} \mathrm{NAA}+0.1 \%$ active carbon $+2.0 \%-5.0 \%$ sodium alginate $+2.0 \%-3.0 \%$ cassava starch 


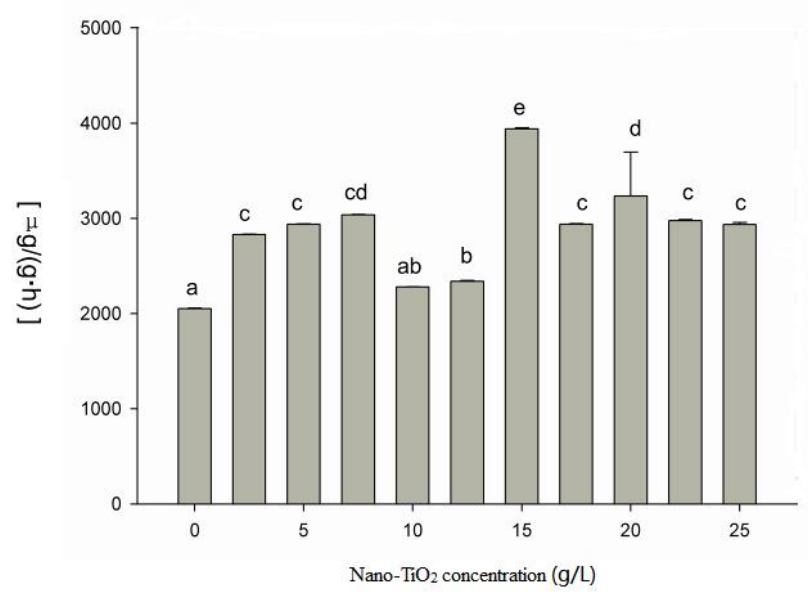

Figure 8 Effect of nano- $\mathrm{TiO}_{2}$ on the root system vigor of $D$. officinale germination seedlings

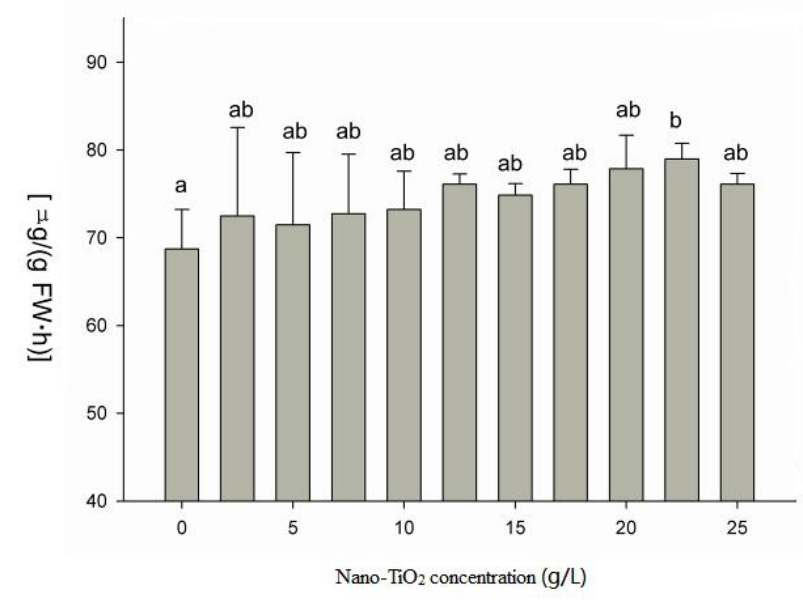

Figre 9 Effect of nano- $\mathrm{TiO}_{2}$ on nitrate reductase activity of $D$. officinale germination seedlings

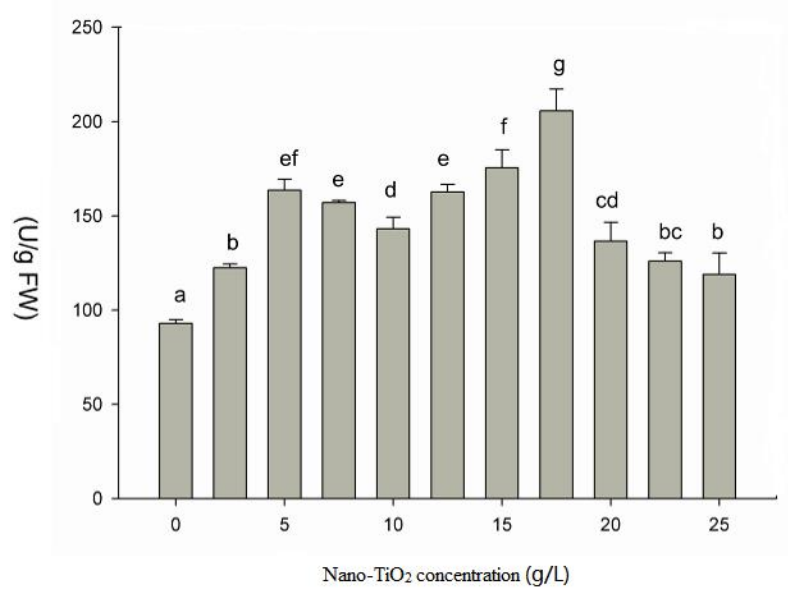

Figure 10 Effect of nano- $\mathrm{TiO}_{2}$ on total SOD activity of $D$. officinale germination seedlings 


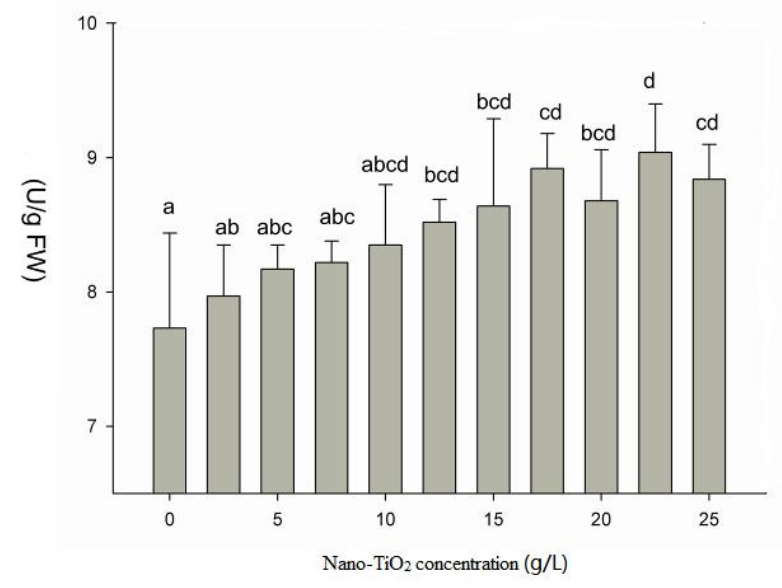

Figure 11 Effect of nano- $\mathrm{TiO}_{2}$ on POD activity of $D$. officinale germination seedlings

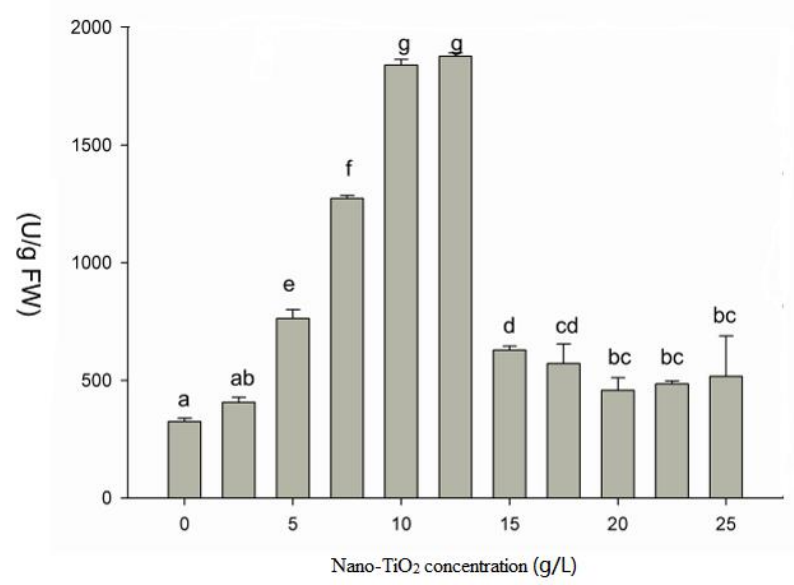

Figure 12 Effect of nano- $\mathrm{TiO}_{2}$ on CAT activity of $D$. officinale germination seedlings

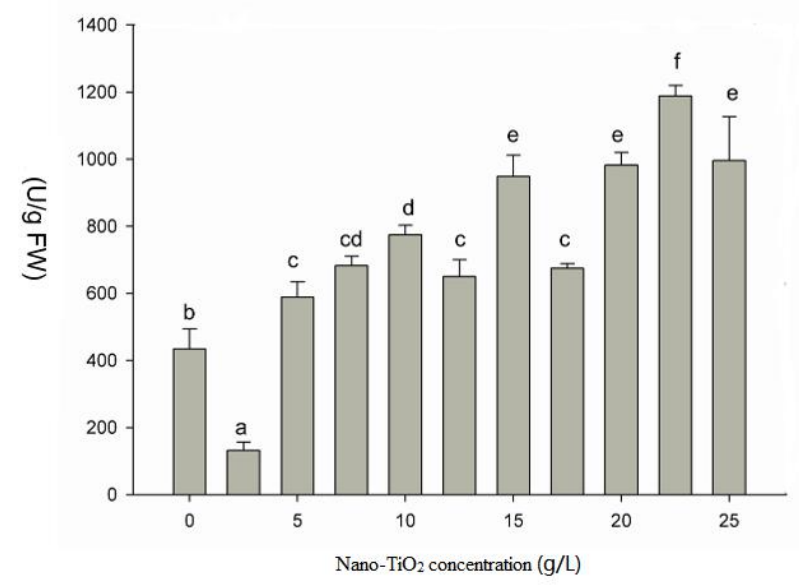

Figure 13 Effect of nano- $\mathrm{TiO}_{2}$ on T-AOC activity of $D$. officinale germination seedlings 
Figures

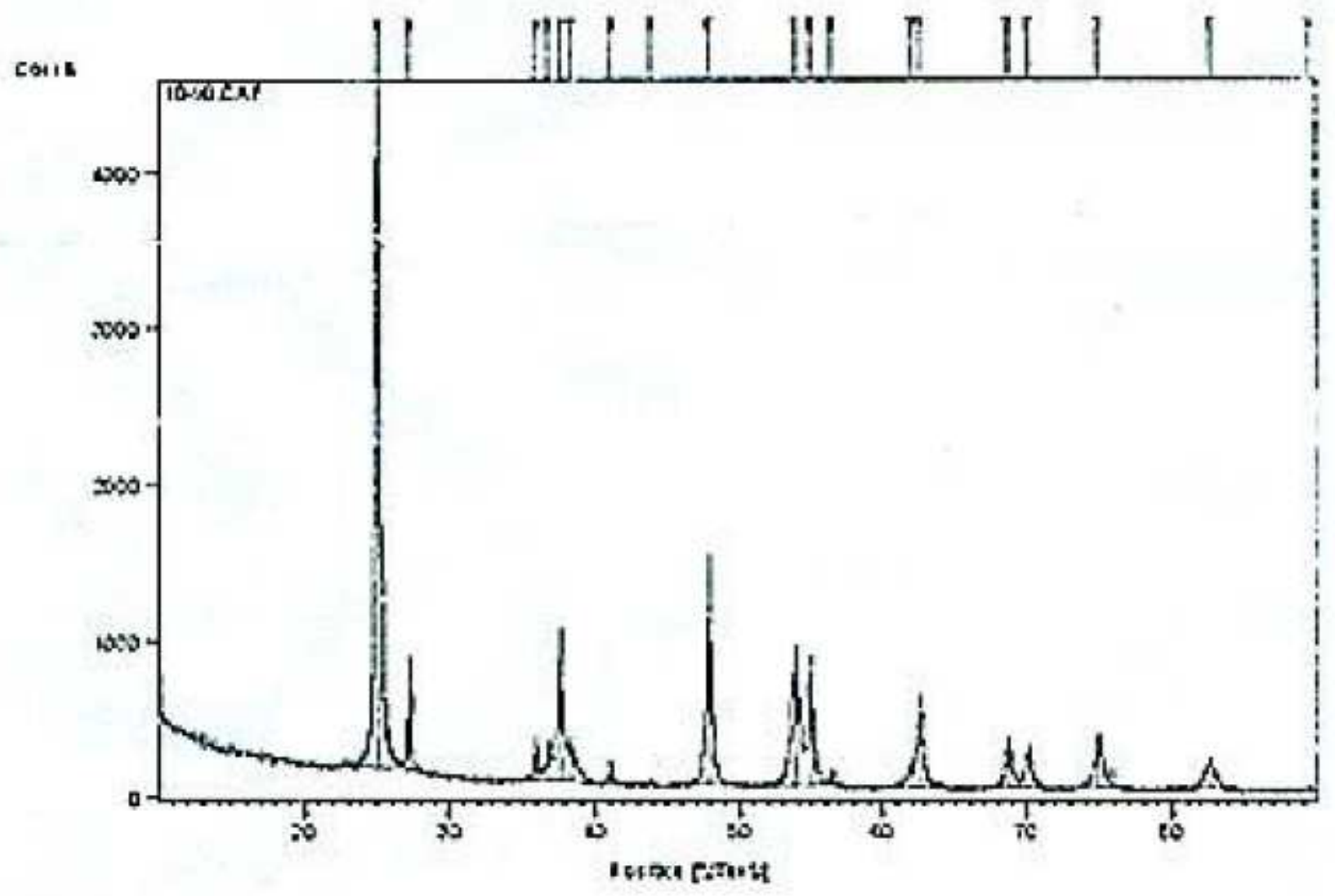

Figure 1

Determination of average grain size of nano-TiO2 sol by X-ray diffraction analysis (peak: $2.6 \mathrm{~nm}$ ) 


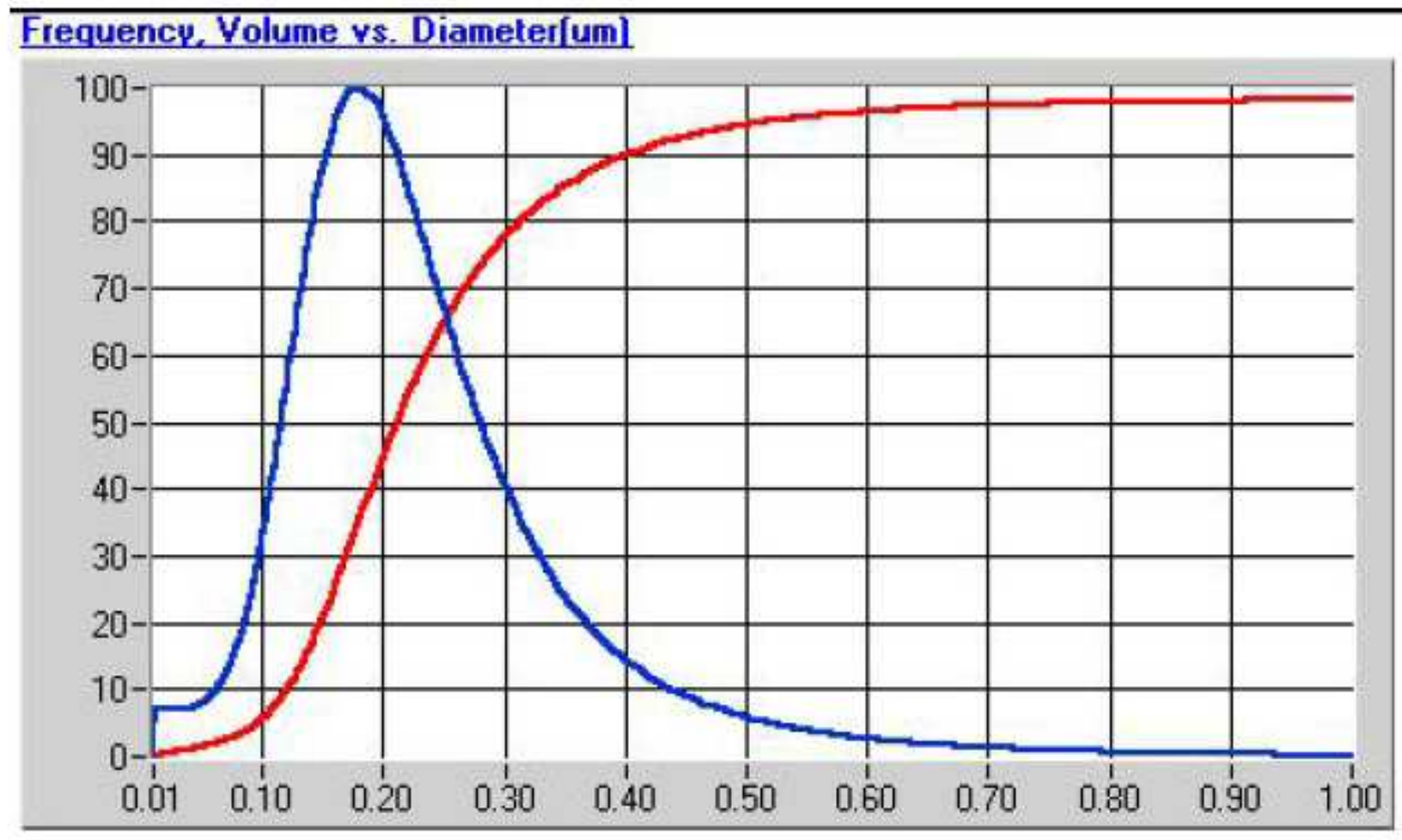

Figure 2

Particle size analysis results of nano TiO2 sol
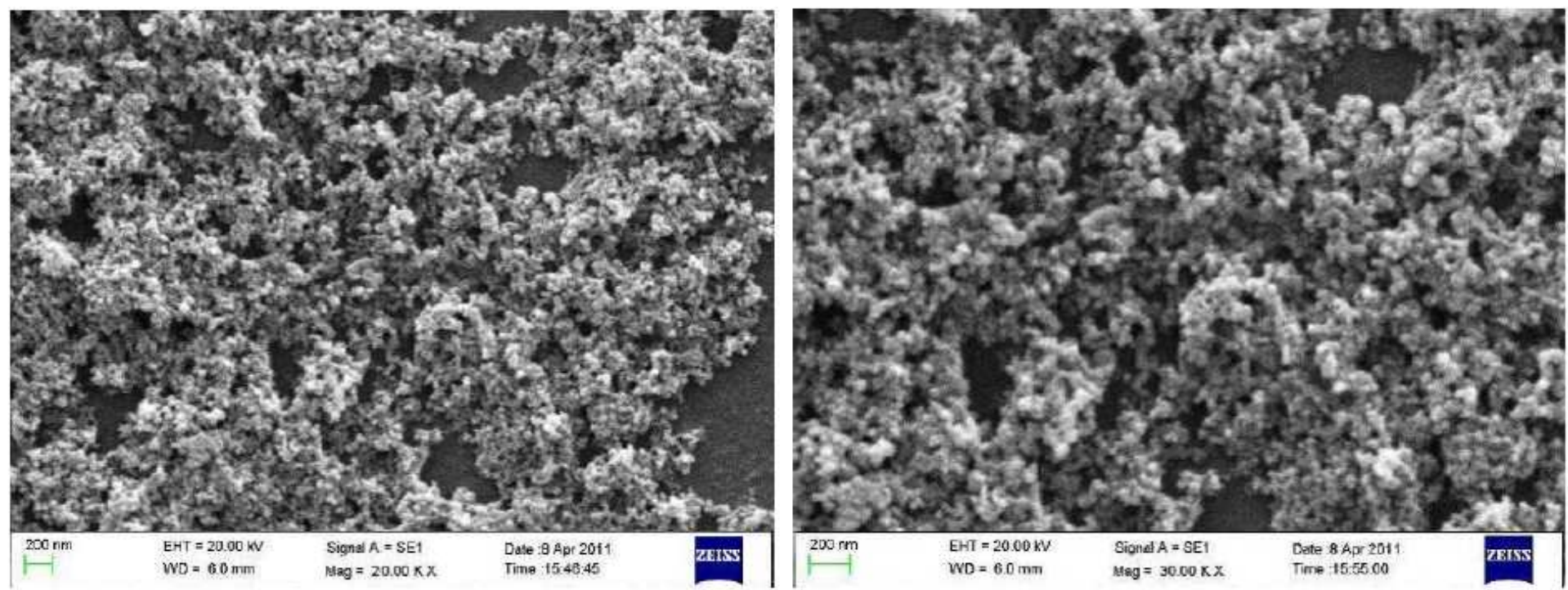

Figure 3

Nano TiO2 sol under scanning electron microscope (A: 20000 times; B: 30000 times) 

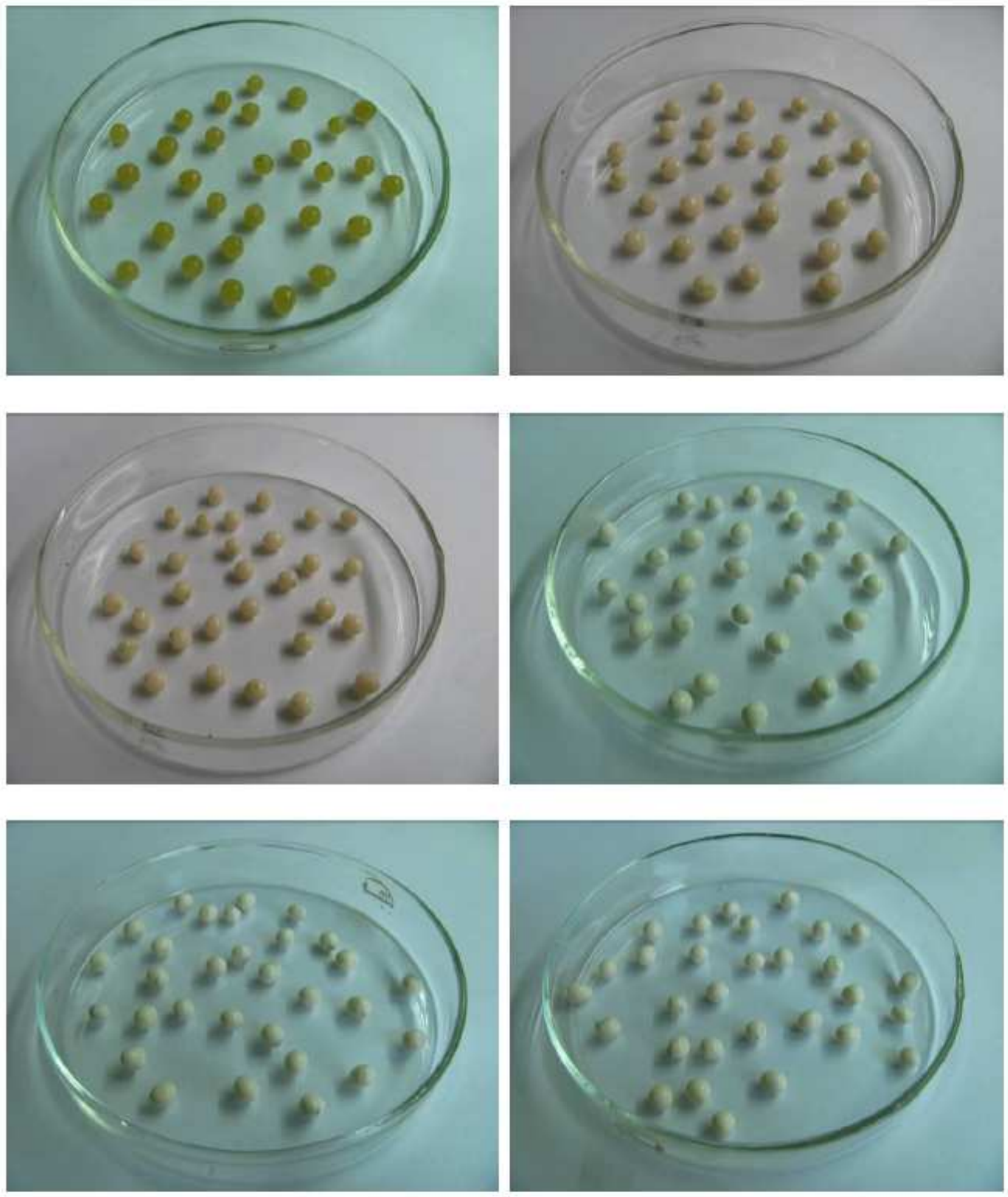

\section{Figure 4}

Synthetic seeds (diameter $=0.5 \mathrm{~cm}$ ) of D. officinale prepared by adding different concentrations of nano$\mathrm{TiO} 2$ (A - F: 0, 1.0, 2.0, 3.0, 4.0, 5.0\% nano-TiO2 concentration respectively), MS + 2.0mg/L 6-BA + $0.5 \mathrm{mg} / \mathrm{L}$ NAA $+3.0 \%$ sodium alginate $+3.0 \%$ cassava starch $+1.0 \%$ water retaining agent for synthetic endosperm 

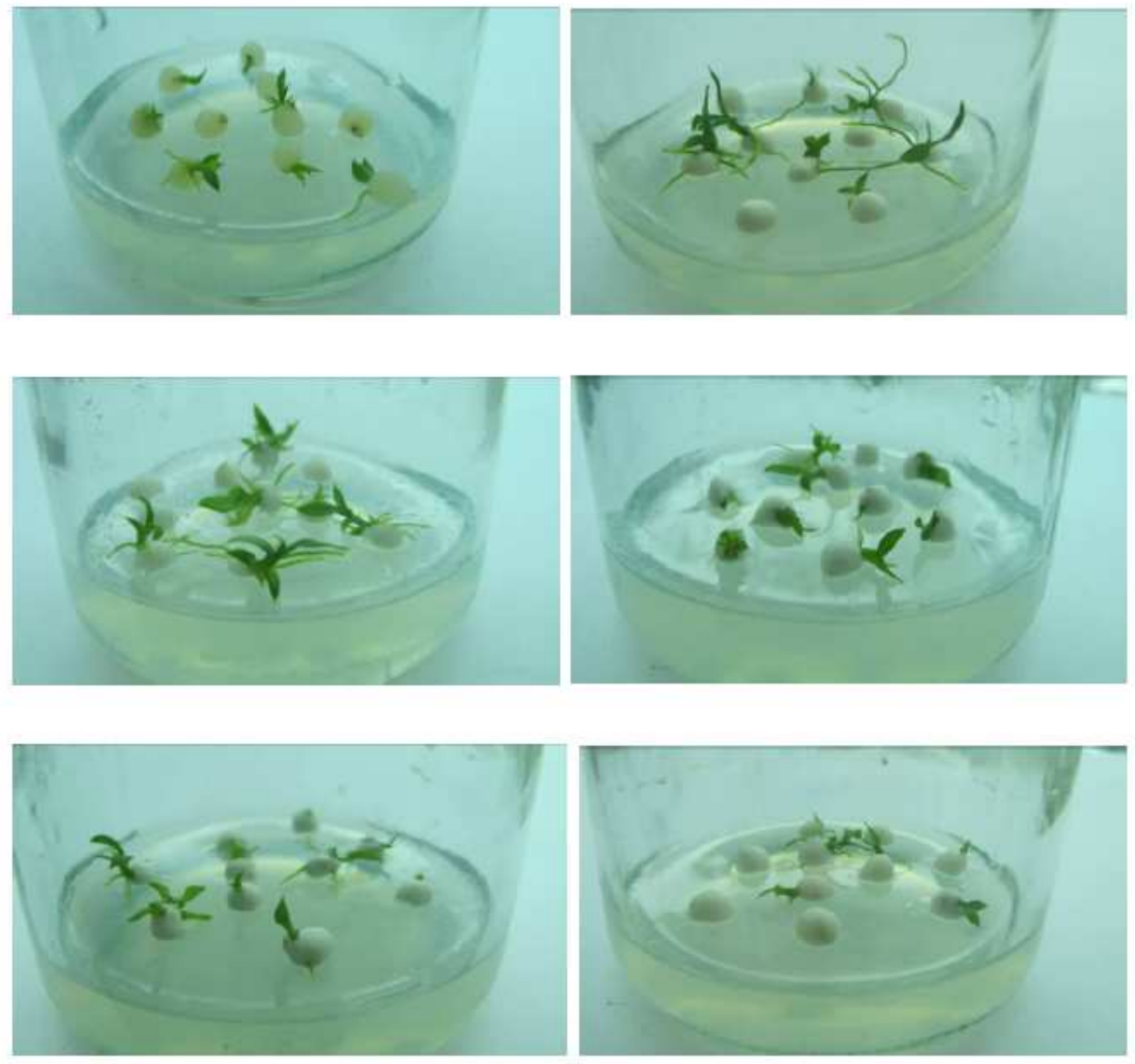

Figure 5

Effect of different concentration of nano-TiO2 on the 60 days seedling formation of $D$. officinale synthetic seeds (diameter $=0.5 \mathrm{~cm}$ ) (A - F: 0, 1.0, 2.0, 3.0, 4.0, 5.0\% nano-TiO2 concentration respectively) 

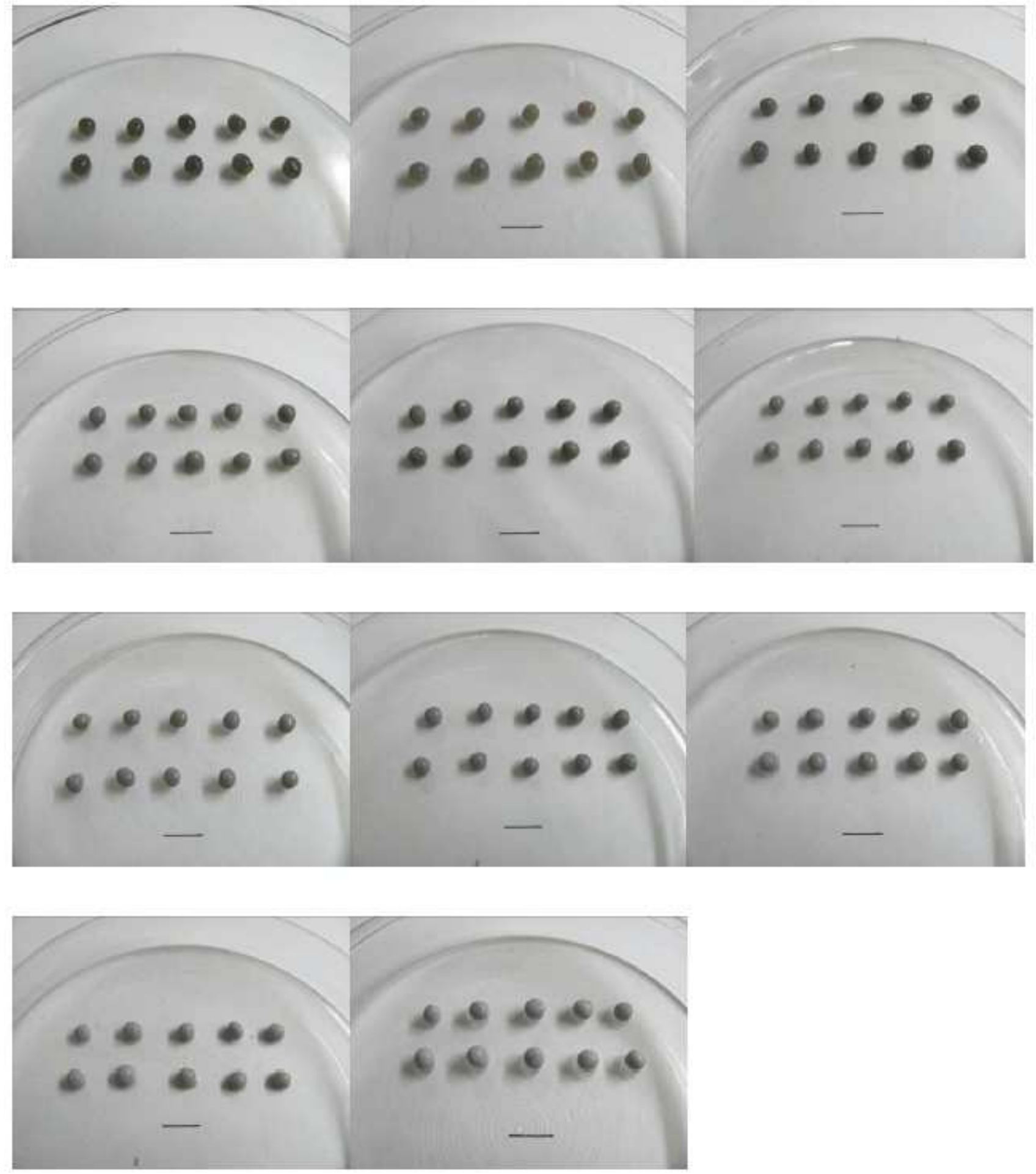

\section{Figure 6}

Nano synthetic seeds of D. officinale: take MS $+2.0 \mathrm{mg} / \mathrm{L} 6-\mathrm{BA}+0.5 \mathrm{mg} / \mathrm{L}$ NAA+ $0.1 \%$ active carbon + $2.0 \%-5.0 \%$ sodium alginate $+2.0 \%-3.0 \%$ cassava starch as basic synthetic endosperm, and add $(0,2.5$, $5.0,7.5,10,12.5,15,17.5,20,22.5,25) \mathrm{g} / \mathrm{L}$ nano-TiO2 (A - K) respectively. The horizontal line represents 1 cm length. 

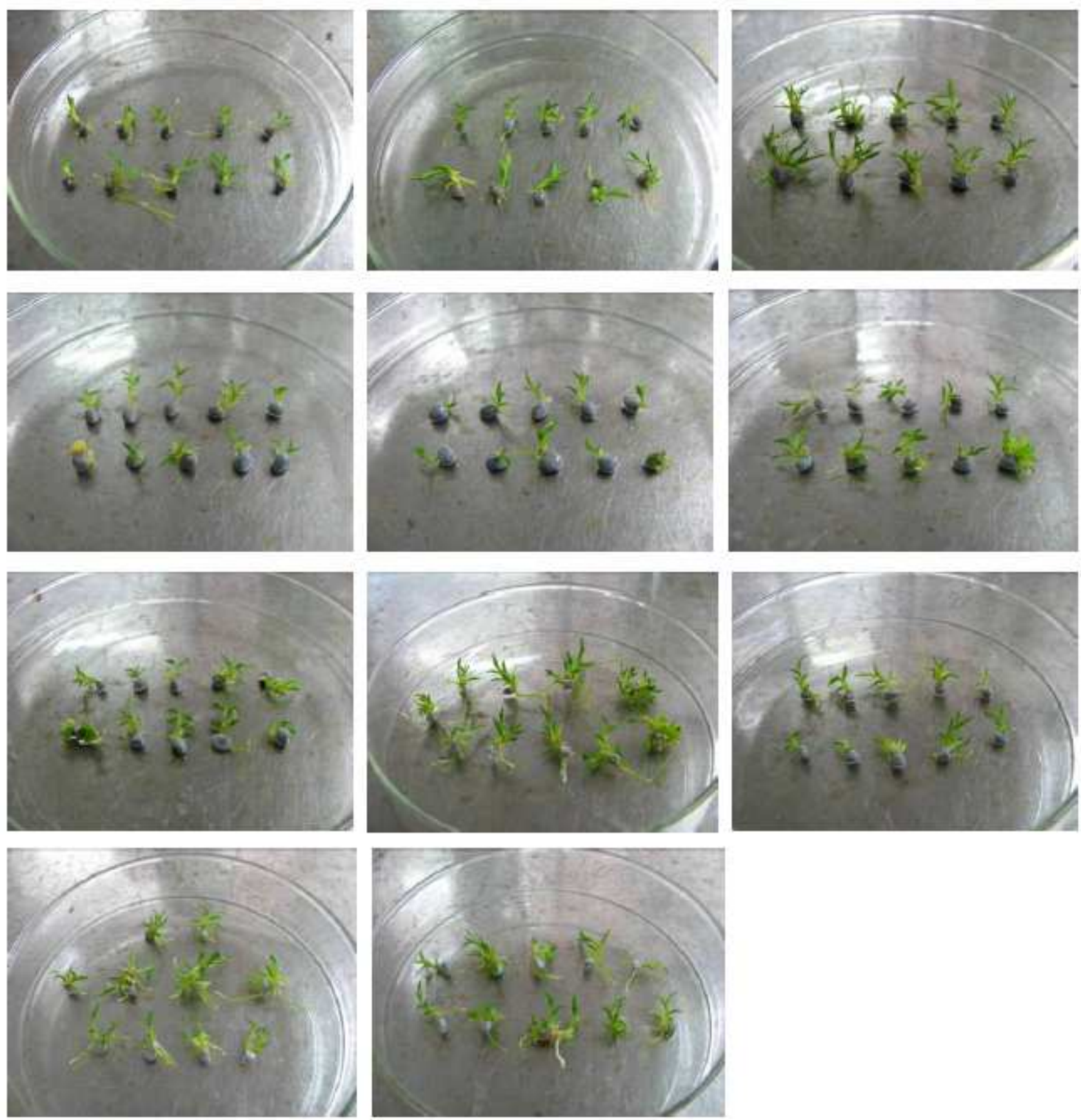

\section{Figure 7}

Effects of different concentrations of nano-TiO2 on the seedling formation of D. officinale synthetic seeds (diameter $=0.5 \mathrm{~cm}$ ) in $60 \mathrm{~d}$ (A - F: adding nano-TiO2 concentration of $0,2.5,5.0,7.5,10,12.5,15$, $17.5,20,22.5,25 \mathrm{~g} / \mathrm{L}$ ), basic synthetic endosperm of $\mathrm{MS}+2.0 \mathrm{mg} / \mathrm{L}$ 6-BA $+0.5 \mathrm{mg} / \mathrm{L}$ NAA $+0.1 \%$ active carbon $+2.0 \%-5.0 \%$ sodium alginate $+2.0 \%-3.0 \%$ cassava starch 


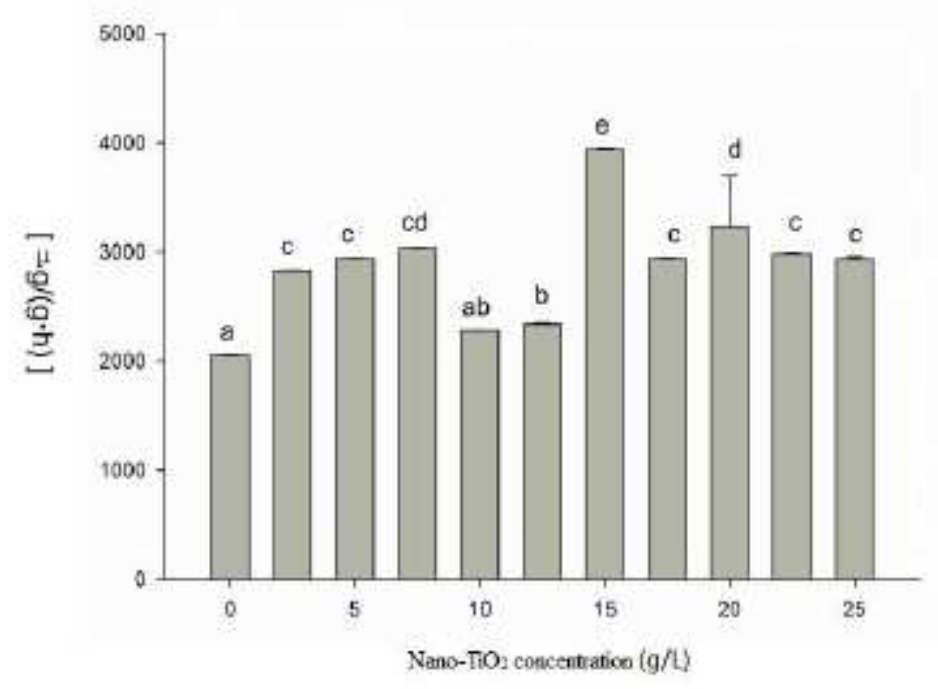

Figure 8

Effect of nano-TiO2 on the root system vigor of D. officinale germination seedlings

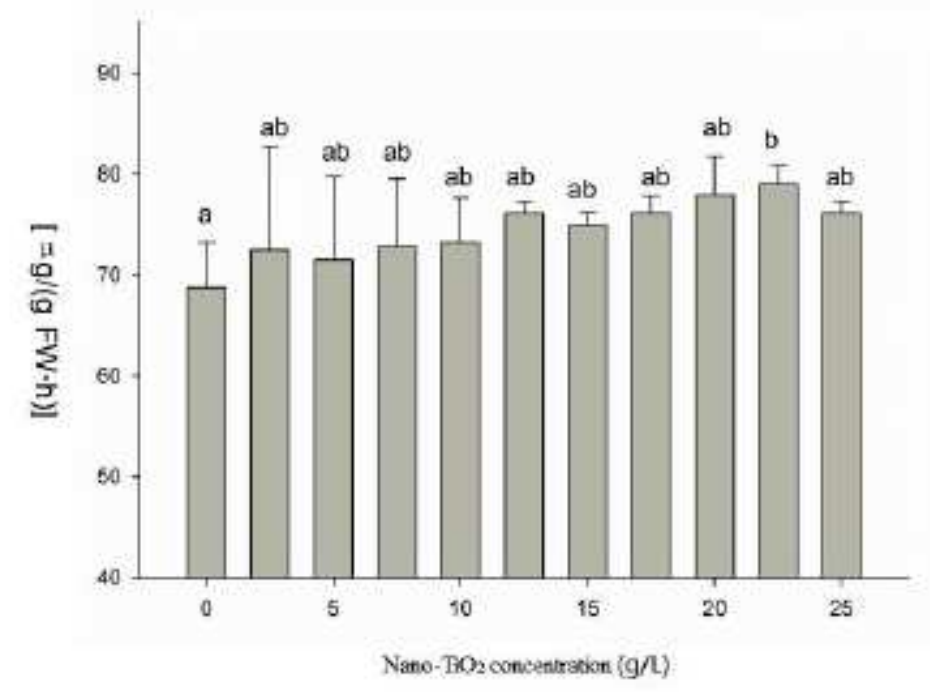

Figure 9

Effect of nano-TiO2 on nitrate reductase activity of D. officinale germination seedlings 


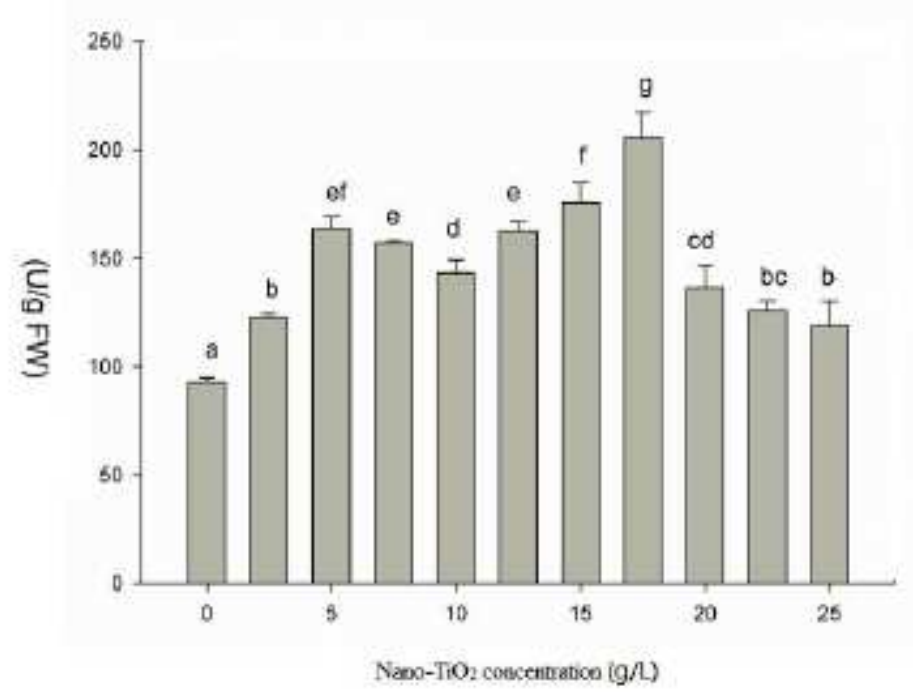

Figure 10

Effect of nano-TiO2 on total SOD activity of D. officinale germination seedlings

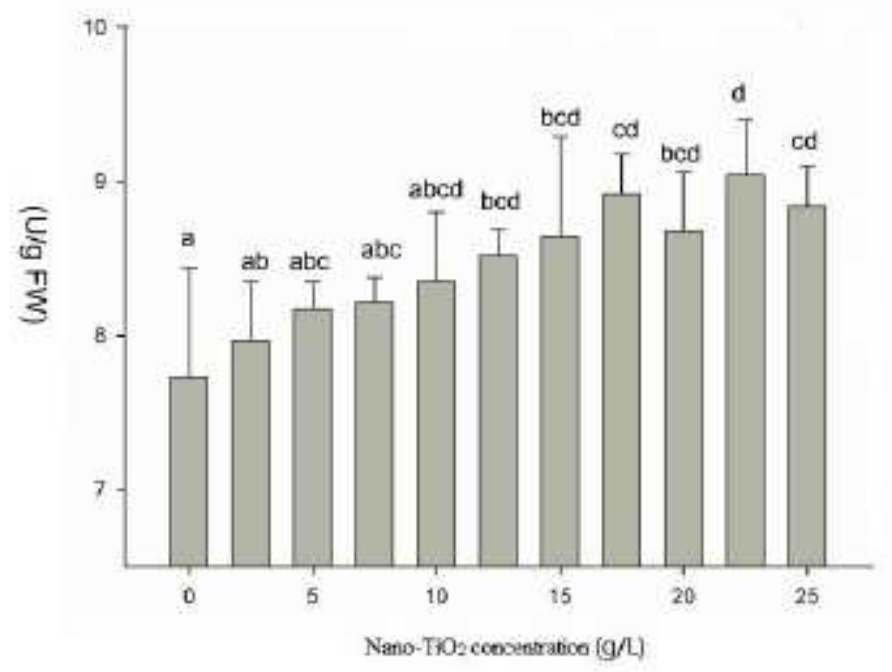

Figure 11

Effect of nano-TiO2 on POD activity of D. officinale germination seedlings 


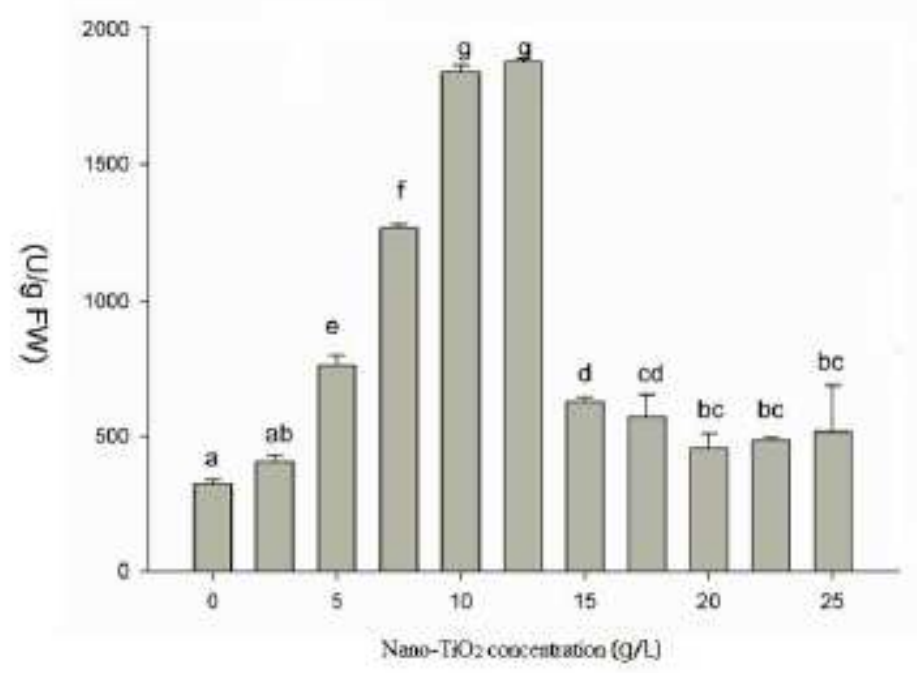

Figure 12

Effect of nano-TiO2 on CAT activity of D. officinale germination seedlings

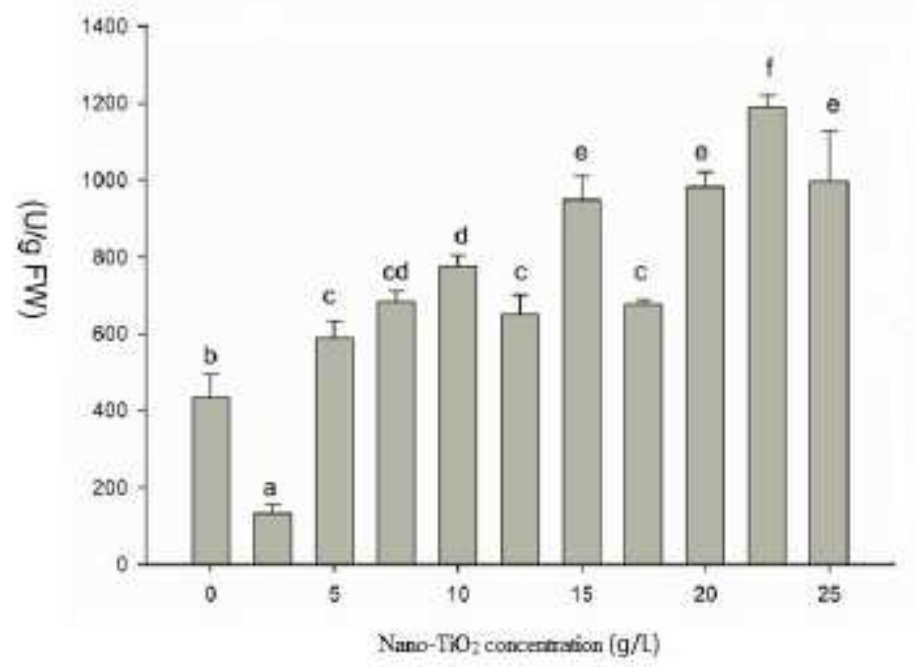

Figure 13

Effect of nano-TiO2 on T-AOC activity of D. officinale germination seedlings 